Illinois State University

ISU ReD: Research and eData

Theses and Dissertations

$5-10-2017$

\title{
The Impact of Ethnic Identity on Psychological Well-being and Perceived Discrimination among Arab Americans
}

Rawan Atari

Illinois State University, rhatari@ilstu.edu

Follow this and additional works at: https://ir.library.illinoisstate.edu/etd

Part of the Clinical Psychology Commons, and the Counseling Psychology Commons

\section{Recommended Citation}

Atari, Rawan, "The Impact of Ethnic Identity on Psychological Well-being and Perceived Discrimination among Arab Americans" (2017). Theses and Dissertations. 743.

https://ir.library.illinoisstate.edu/etd/743

This Thesis is brought to you for free and open access by ISU ReD: Research and eData. It has been accepted for inclusion in Theses and Dissertations by an authorized administrator of ISU ReD: Research and eData. For more information, please contact ISUReD@ilstu.edu. 


\title{
THE IMPACT OF ETHNIC IDENTITY ON PSYCHOLOGICAL WELL-BEING AND PERCEIVED DISCRIMINATION AMONG ARAB AMERICANS
}

\author{
Rawan Atari
}

\section{Pages}

The current study intended to expand upon psychological research on the Arab American community, which has faced increased discrimination since 9/11 and recent ISIS-related terrorist attacks. Since perceived discrimination has been associated with greater psychological distress among Arab Americans, it is important to determine whether any protective factors are available for this community. In a sample of Arab Americans, the relationship between perceived discrimination and aspects of psychological well-being (i.e., self-esteem, flourishing, and satisfaction with life) were examined in order to gain a better overall picture of Arab American mental health. Because ethnic identity has been recognized as a protective factor against discrimination for other minority groups, it was examined as such for the current sample. Ethnic identity exploration, resolution, and affirmation were studied in relation to psychological wellbeing, and ethnic identity was studied as a moderator between perceived discrimination and psychological well-being. A recent typology created by Umaña-Taylor, Yazedjian, and BámacaGómez (2004) was used to classify participants into ethnic identity clusters based on degrees of exploration, resolution, and affirmation. The sample comprised 156 self-identified Arab Americans living in the United States who were at least 18 years of age. Results from multiple regression analyses demonstrated that perceived discrimination was negatively related to selfesteem and flourishing. Ethnic identity exploration was not significantly related to psychological 
well-being. However, ethnic identity resolution and affirmation were significantly, positively related to self-esteem, flourishing, and satisfaction with life. Ethnic identity affirmation appeared to be a moderator by mitigating the impact of perceived discrimination on flourishing. Based on Umaña-Taylor and colleagues' (2003) typology, four ethnic identity clusters emerged using a hierarchal cluster analysis, and participants fell into one of the following: (a) Achieved Positive, (b) Diffuse Positive, (c) Moratorium Positive, and (d) Diffuse Negative. Findings are generally consistent with previous research among various minority groups, as well as Erikson's (1968) theory and Tajfel's (1981) theory. However, the current study suggests that it may be ethnic identity affirmation that serves as protective factor against discrimination, rather than ethnic identity exploration or resolution. Therefore, future studies are encouraged to study the components of ethnic identity independently of one another.

KEYWORDS: Arab American, Perceived discrimination, Psychological well-being, Ethnic identity 


\title{
THE IMPACT OF ETHNIC IDENTITY ON PSYCHOLOGICAL WELL-BEING AND PERCEIVED DISCRIMINATION AMONG ARAB AMERICANS
}

\author{
RAWAN ATARI
}

A Thesis Submitted in Partial Fulfillment of the Requirements for the Degree of

MASTER OF SCIENCE

Department of Psychology

ILLINOIS STATE UNIVERSITY 
Copyright 2017 Rawan Atari 


\title{
THE IMPACT OF ETHNIC IDENTITY ON PSYCHOLOGICAL WELL-BEING AND PERCEIVED DISCRIMINATION AMONG ARAB AMERICANS
}

\author{
RAWAN ATARI
}

COMMITTEE MEMBERS:

Suejung Han, Chair

Jeffrey Kahn 


\section{ACKNOWLEDGMENTS}

First and foremost, thank you to my family for your never ending support and love. To my mother, Hanaa, I truly believe that none of this would have been possible without your encouragement. You've given me the strength to pursue my education to the fullest extent, and I not only do it for myself, but I do it for you as well. Thank you for teaching me the importance of what it means to be a student in life.

To my brother, Sami, and my sisters, Aseel and Razan. The fact that you all have believed in me so much and allowed me to be the person I am means the world to me. Thank you for always being there whenever I need you, especially during these last two years.

To my first mentor, Dr. Enaya Othman, I appreciate your influence in my life in so many ways. You've empowered me and encouraged me to dedicate my research to something that I am truly passionate about. Your guidance is tremendous, and I aspire to continuously learn from you.

R. A. 


\section{CONTENTS}

Page

ACKNOWLEDGMENTS

CONTENTS

TABLES

FIGURES vi

CHAPTER I: THE PROBLEM AND ITS BACKGROUND 1

Statement of the Problem 1

Definition of Terms

Ethnic identity 3

$\begin{array}{ll}\text { Perceived ethnic discrimination } & 4\end{array}$

$\begin{array}{ll}\text { Arab American } & 4\end{array}$

$\begin{array}{ll}\text { Flourishing } & 4\end{array}$

$\begin{array}{ll}\text { Satisfaction with life } & 4\end{array}$

$\begin{array}{ll}\text { Self-esteem } & 5\end{array}$

CHAPTER II: REVIEW OF THE LITERATURE 6

$\begin{array}{ll}\text { Arab Americans } & 6\end{array}$

$\begin{array}{ll}\text { Discrimination against Arab Americans } & 10\end{array}$

Discrimination against and psychological well-being of Arab Americans $\quad 12$

$\begin{array}{ll}\text { Ethnic Identity } & 14\end{array}$

$\begin{array}{ll}\text { Identity and ethnic identity } & 15\end{array}$

$\begin{array}{lr}\text { Ethnic identity in Arab Americans } & 18\end{array}$

Ethnic identity and well-being 19 
$\begin{array}{ll}\text { Ethnic identity as a protective factor against discrimination } & 21\end{array}$

Ethnic identity as a protective factor against discrimination in Arab Americans 22

$\begin{array}{ll}\text { Current Study } & 23\end{array}$

$\begin{array}{ll}\text { Research questions and hypotheses } & 25\end{array}$

$\begin{array}{ll}\text { CHAPTER III: METHODOLOGY } & 27\end{array}$

$\begin{array}{ll}\text { Participants } & 27\end{array}$

$\begin{array}{ll}\text { Eligibility } & 27\end{array}$

$\begin{array}{ll}\text { Sample size } & 27\end{array}$

$\begin{array}{ll}\text { Recruiting } & 27\end{array}$

$\begin{array}{ll}\text { Participant characteristics } & 28\end{array}$

$\begin{array}{ll}\text { Instruments } & 31\end{array}$

$\begin{array}{ll}\text { Socio-demographic questionnaire } & 31\end{array}$

$\begin{array}{ll}\text { Ethnic identity measures } & 32\end{array}$

$\begin{array}{ll}\text { Psychological well-being measures } & 33\end{array}$

$\begin{array}{ll}\text { Perceived discrimination measure } & 34\end{array}$

$\begin{array}{ll}\text { Procedures } & 35\end{array}$

$\begin{array}{ll}\text { Data Analysis Plan } & 36\end{array}$

$\begin{array}{ll}\text { CHAPTER IV: RESULTS } & 37\end{array}$

$\begin{array}{ll}\text { Description of Study Variables } & 37\end{array}$

Research Question \& Hypotheses Testing $\quad 41$

$\begin{array}{ll}\text { Exploratory research question } 1 & 41\end{array}$

$\begin{array}{ll}\text { Self-esteem } & 46\end{array}$ 
Satisfaction with life $\quad 51$

CHAPTER V: DISCUSSION

Description of Study Variables

Ethnic Identity Status among Arab Americans $\quad 55$

Perceived Discrimination and Psychological Well-Being 58

Ethnic Identity and Psychological Well-Being $\quad 59$

Ethnic Identity as Buffer against Perceived Discrimination $\quad 62$

$\begin{array}{ll}\text { Limitations } & 64\end{array}$

$\begin{array}{ll}\text { Clinical Implications } & 65\end{array}$

$\begin{array}{ll}\text { Future Considerations } & 67\end{array}$

$\begin{array}{ll}\text { REFERENCES } & 70\end{array}$

APPENDIX A: MEASURES $\quad 82$ 


\section{TABLES}

Table

Page

1. Frequency Distribution - Employment status

2. Frequency Distribution - Socioeconomic status

3. Means, Standard Deviations, Range of Study Variables

4. Intercorrelations among Ethnic Identity Dimensions and Predictor Variables

5. Frequency Distribution: Eight ethnic identity clusters

6. Moderated Regression Analysis on Self-esteem

7. Moderated Regression Analysis on Flourishing

50

8. Moderated Regression Analysis on Satisfaction with Life 


\section{FIGURES}

Figure Page

1. Ethnic Identity Statuses identified through cluster analysis 45

2. Ethnic Identity Affirmation as a Moderator of the relationship between Perceived Discrimination and Flourishing 


\section{CHAPTER I: THE PROBLEM AND ITS BACKGROUND}

\section{Statement of the Problem}

The United States demographics are currently undergoing a change as ethnic groups traditionally categorized as the minority of the population are now becoming the majority in many states (U.S. Census Bureau, 2010). Increasing scholarly attention thus has been paid to these rapidly growing, yet understudied, ethnic minority populations (e.g., Lee, 2003; Phinney; 1996; Umaña-Taylor, Yazedjian, \& Bámaca-Gómez, 2004). Nonetheless, much of the research has been centered on larger groups such as African Americans, Asian Americans, and Latin Americans (e.g., Chavira \& Phinney, 1991; Lee; 2003; White \& Burke, 1987), and psychological literature on Arab Americans has been relatively limited. Despite their obvious minority status in the United States, Arab Americans are classified as "White" and are not recognized as a minority group by the United States government (Awad, 2010), resulting in a large undercount in the Arab American community (Arab American Institute, 2015) and limited data on them as minorities. Most of the small number of studies that examined Arab Americans specifically focused on the effects of perceived discrimination on mental health (e.g., Sirin \& Fine, 2007; Moradi \& Hassan, 2003) and the process of cultural adaptation in relation to psychological distress (e.g., Amer, 2007; El-Sayed \& Galea, 2009; Ghanem-Ybarra, 2003). Researchers have called on the community to expand on the psychological investigation of Arab Americans (Awad, 2010; Britto, 2008).

After the terrorist attacks on September 11, 2001, the sociopolitical context of the West shifted, and, as a result, the way in which Arab Americans are viewed shifted as well (Ibish, 2003, 2008). Due to the biased perceptions present in the media and the racialization patterns in the United States, Arabs and Muslims have been "Othered” (AAI, 2007; Jamal, 2008). 
"Othering," as described by Said (1978), refers to making the fundamental differences that exist between groups of people due to ethnic origin, race, religion, and family country of origin salient. When "othering" occurs, people who are seen as unusual or different than the collective norm of society are alienated from the majority. The Othering process of Arabs and Muslims leaves this group of ethnic minorities vulnerable to discrimination that may predispose them to acquire mental health problems (Jamal, 2008; Finch, Kolody, \& Vega, 2000). Hate crimes targeting the Arab American community increased by $1600 \%$ after $9 / 11$ (CNN.com, 2002), and, due to recent events carried out by the Islamic State of Iraq and Syria (ISIS), more reports on acts of violence against Arab Americans, or those perceived to be Arab, are continuously being received (Ajrouch, 2005; Naeem, 2015). Also, prejudicial attitudes towards Arab Americans appear to be higher compared to any other ethnic minority groups (Bushman \& Bonacci, 2004). Because perceived discrimination appears to negatively influence the psychological well-being of Arab Americans (Amer, 2007), it is imperative to examine whether any protective factors are available for this population in order to help individuals navigate through acts of discrimination by lessening their degree of impact on mental health.

For ethnic minorities in general, ethnic identity has largely been predicted to be a protective factor against the negative impacts of discrimination (Phinney, 2003). The construct of ethnic identity in Arab Americans has been scarcely examined by researchers, although it has been demonstrated to be beneficial to other ethnic minority groups (Lee, 2003; Phinney, 2003). The limited body of research that examined Arab American ethnic identity found that individuals with a greater sense of ethnic identity displayed increased psychological well-being and were less likely to report experiences of discrimination than Arab Americans with a weaker sense of ethnic identity (Sheldon, Oliver, \& Balaghi, 2015; Willems, 2012). After the terror attacks on 
9/11, Arab Americans reported numerous resources and coping strategies that helped them navigate their way through adversity, one of which was an identity that was grounded in their familial relationships, religion, and culture (Betein \& Allen, 2005). As ethnic identity is considered to be one of the most important psychological resources that contributes to an individual's resilience (Phinney, 1990; Phinney, 2003), it is important to study the extent to which ethnic identity can serve as a protective factor for Arab Americans who are an increasing target for acts of discrimination and prejudicial attitudes.

To the best of my knowledge, only one study examined the ethnic identities of Arab Americans in relation to their psychological well-being. Sheldon, Oliver, and Balaghi (2015) found that Arab American adolescents with a greater degree of ethnic identity demonstrated a heightened sense of self-acceptance, as well as an increased sense of a meaningful life.

In sum, the present study examined the negative contribution of discrimination on psychological well-being in order to gain a better overall understanding of the impact perceived discrimination has on the mental health of people of color. Additionally, the present study explored the positive contribution of ethnic identity in Arab Americans in order to examine whether ethnic identity may serve as a potential protective factor against perceived discrimination.

\section{Definition of Terms}

\section{Ethnic identity}

The definition of ethnic identity that has been the most widely used and accepted maintains, "ethnic identity is a dynamic, multidimensional construct that refers to one's identity, or sense of self as a member of an ethnic group" (Phinney, 2003, p. 63). For the purpose of the 
current study, ethnic identity was measured by using the Ethnic Identity Scale (Umaña-Taylor et al., 2004).

\section{Perceived ethnic discrimination}

Perceived ethnic discrimination was operationally defined as the frequency with which an individual experiences discriminatory events in the past year. In the current study, perceived ethnic discrimination was measured using the Schedule of Racist Events Modified for Use with Arab American Persons (SRE-AA; Moradi \& Hasan, 2004).

\section{Arab American}

For the current study, Arab American was operationally defined as an individual living in the United States who has ancestry in any of the following 22 Arab countries: Lebanon, Syria, Egypt, Palestine, Iraq, Algeria, Bahrain, the Comoros Islands, Djibouti, Jordan, Kuwait, Libya, Morocco, Mauritania, Oman, Qatar, Saudi Arabia, Somalia, Sudan, Tunisia, the United Arab Emirates, and Yemen. Arab American identification was self-reported in the socio-demographic questionnaire that asks participants to select their country of origin.

\section{Flourishing}

Flourishing was operationally defined as an individual's perceived level of success in areas of optimism, purpose, self-esteem, and relationships. It was utilized as a component of psychological well-being. The current study measured flourishing using the Flourishing Scale (Diener et al., 2009).

\section{Satisfaction with life}

Satisfaction with life was operationally defined as an individual's own evaluation of her or his overall life, including the past and up until the present. Life satisfaction has been identified 
as a component of subjective psychological well-being and was used as such in the current study.

It was measured by the Satisfaction with Life Scale (Diener, Emmons, Larsen, \& Griffen, 1985). Self-esteem

For the current study, self-esteem was operationally defined as an individual's sense of global self-worth and general feelings of self-acceptance, worthiness, self-respect, and goodness. The current study measured self-esteem with the widely used self-report measure, the Rosenberg Self-Esteem Scale (Rosenberg, 1965). 


\section{CHAPTER II: REVIEW OF THE LITERATURE}

\section{Arab Americans}

Arab Americans are a diverse group of people who trace their roots to the Arab world and have been settling in the United States since the 1880s. Although the definition of what constitutes an Arab American has been debated as either a linguistic or cultural term, the Arab American Institute (AAI) provides the most exclusive definition. Arab Americans, both Christians and Muslims, are individuals who have ancestry in any of the following 22 Arab countries: Lebanon, Syria, Egypt, Palestine, Iraq, Algeria, Bahrain, the Comoros Islands, Djibouti, Jordan, Kuwait, Libya, Morocco, Mauritania, Oman, Qatar, Saudi Arabia, Somalia, Sudan, Tunisia, the United Arab Emirates, and Yemen (AAI, 2011).

As the terms "Middle Eastern" and "Arab" tend be used interchangeably, it is important to differentiate between the two due to the inclusion of non-Arabic speaking countries in Middle Eastern boundaries. Western geographers and historians have largely debated the countries that comprise the Middle East. By the mid-20th century the common definition of the Middle East encompassed the non-Arabic speaking countries of Turkey, Cyprus, Iran, and Israel (Encyclopedia Britannica Online, n.d.). The term "Middle Eastern" speaks to an individual from a particular geographic location, extending from Morocco to the Arabian Peninsula and Iran. The term "Arab" refers to a person whose language is Arabic and who originates from an Arabic speaking country (AAI, 2011).

Arab Americans make up an ethnicity of three major immigration waves of people that travelled to the United States from Arabic-speaking countries in southwestern Asia and North Africa. The first wave of immigrants primarily consisted of Christian laborers, merchants, and 
farmers from countries such as Syria and Lebanon. These immigrants sought out economic stability in the late 1800s and the early 1900s. The second wave of immigration consisted of more Muslims from countries such as Palestine, Jordan, and Egypt, including those displaced from their homes due to the establishment of the state of Israel in 1948. The third wave of immigration brought in more Muslims characterized as highly educated professionals, as well as those looking to escape war and political instability in their homeland. During this third wave of immigration, immigrants from countries whose people did not previously immigrate to the states, such as Iraq, began to flee their country in large numbers and settle in the United States (AANM, 2000).

As noted by the AAI, the population of Arab Americans has reached around 3.7 million. However, the U.S. Census estimates the number of Arab individuals living in the United States to be at 1.8 million. The discrepancy in estimates is largely due to the lack of ethnic category for Arab Americans on the U.S. Census (AAI, 2007). In terms of racial classification, according to the U.S. Census, people from the Middle East or North Africa are considered "White/Caucasian". Arab Americans may choose to select "Some Other Race" and write in their ethnicity or country of origin as a refusal to self-identify as 'White/Caucasian'. Arab Americans face a conflict in terms of racial classification because although the U.S. Census Bureau classifies them as 'White/Caucasian', the government's war on terror has labeled Arabs as an "other" and places them in opposition with Whites (Howell \& Shyrock, 2003). The AAI advocates on behalf of the Arab American community and is currently working with the Census Bureau to broaden its options pertaining to ancestry by including a Middle Eastern/North African racial category in the 2020 Census and adding a space to further specify ethnic origin. The AAI asserts that the significant undercount of the Arab American community has served as a barrier 
to education, health, and employment opportunities for this community and impacts the overall representation of a significant portion of the U.S. population (AAI, 2015).

Although Arab Americans are often presumed to be Muslims, statistics shows that Christians make up the majority of the Arab American population at an estimate of $77 \%$. Contrary to popular belief, Arab American Muslims only make up approximately 23\% of the Arab American population (AAI, 2012). Perceptions of Arab Americans often overlook their religious classification as they are assumed to be Muslim and are talked about monolithically. This may be due to more overt religious markers, such as a woman's hijab or a man's long beard, which make Arab American Muslims a more visible minority than Christian Arabs. Arab American Muslims are impacted by this increased visibility, as they are more vulnerable to experiences of prejudice and discrimination (Awad, 2010). Additionally, Arab American Muslims are more likely to identify with their Arab heritage, as compared to Christian Arab Americans who are more likely to identify as White rather than Arab (Read, 2003). The difference in self-identification between the two religious groups may be attributed to the fact that Arab culture is embedded into Islam, and the sociopolitical divides in the Middle East between Arab Christians and Arab Muslims have been present consistently though history to present day (Read, 2008). Although the majority of Arab Americans from the first wave of immigration are Christian immigrants, Arab American Muslims are the fastest growing portion of the community today (AAI, 2012).

As the multitude of immigration waves led Arab immigrants to settle in a myriad of states, today they are currently found in every state in the U.S. However, more than two-thirds of Arab Americans live in the following ten states: California, Michigan, New York, Florida, Texas, New Jersey, Illinois, Ohio, Pennsylvania, and Virginia. Metropolitan Los Angeles, 
Detroit, and New York are home to about one-third of the population. The majority of Arab Americans are born in the United States and about $82 \%$ of Arabs in the United States are U.S. citizens. The majority can trace their ancestry back to Lebanon, Syria, Palestine, Egypt, and Iraq (AAI, 2012).

During the second wave of immigration, Arab students began seeking higher education in the United States, and many of those individuals decided to settle in the states after accepting job offers (Arab American National Museum \& Institute of Museum and Library Services, 2000). Compared to Americans at large, the Arab American population appears to prosper in terms of education and income level. In 2008 about 45\% of Arab Americans had a bachelor's degree or higher compared to $27 \%$ of Americans at large. Approximately 18\% of Arab Americans had a post-graduate degree, which was nearly twice the $10 \%$ average of Americans. The median annual income for Arab American households in 2008 was $\$ 56,331$ compared to $\$ 51,369$ for all American households. The mean individual income for Arab Americans is $27 \%$ higher than the national average, with about $13.7 \%$ of Arab Americans living under the poverty line. About $65 \%$ of Arab American adults work in the labor force, similar to the national average, with an unemployment rate of 5\% for Arab Americans. Most Arab Americans work in the private sector, about $88 \%$, compared to those who are employed by the government at $12 \%$ (AAI, 2012).

The most recent data available state that, similar to most foreign-born segments of the population, the median age of Arab Americans is younger than the average American. The median age of Arab Americans is 30.8 years compared to 35.4 years in the total American population. There is also a higher male-to-female ratio among Arab Americans, with a ratio of 1.12 to 1 . Arab Americans have a higher percentage of marriage and a slightly lower rate of divorce compared to the average of Americans at large (Samhan, 2000). 


\section{Discrimination against Arab Americans}

Discrimination against Arab Americans has been documented from as early as the 1900's (Naber, 2000). Even before the terror attacks on September 11, 2001, stereotypes perpetuated by the media against Arabs were skewed in a negative light. Arab men have been portrayed as barbaric, violent, corrupt, women abusers who commit acts of terrorism (Shaheen, 1984). Longtime media critic Jack Shaheen reviewed hundreds of American films that depict negative stereotypes of Arabs as follows:

“Sub-humans and fanatics who believe in a different god, who don't value life as much as we do, [and who are] intent on destroying us (the west) with their oil or with their terrorism. The men seek to abduct and brutally seduce our women; they are without family and reside in a primitive place (the desert) and behave like primitive beings. The women are subservient resembling black crows — or we see them portrayed as mute, somewhat exotic harem maidens" (Shaheen, Interview, November 25, 2009).

Since the rise of crises in the Middle East, backlash against mosques and Arab-owned businesses in the United States have been on the rise (Brittingham \& de la Cruz, 2005). The June War of 1967 specifically instigated a shift of consciousness among Arabs living in the United States. For much of the Arab American community the 1967 War signified a confirmed alliance between the U.S. and Israel, giving the Arab American community an increasing sense of exclusion from the political process (Suleiman \& Abu Laban, 1989). Arab Americans started to share in experiences of other minority communities in the United States and felt as if they were treated as inferior to the majority White/Caucasian population (Naber, 2000). In 1995, after the Oklahoma City bombing, Arab and Muslim Americans were the targets of more than 200 hate crimes (Brittingham \& de la Cruz, 2005). Historically speaking, Arab Americans have been 
viewed as different than the majority culture due to their unique heritage, and they have experienced some form of discrimination and prejudice. As demonstrated, the form of discrimination and prejudice that Arab Americans experience has altered throughout the years and appears to be contingent upon current world events.

The events that occurred on 9/11 created a dramatic increase in acts of discrimination and prejudice towards people of Arab and Middle Eastern descent (Naber, 2000; Ajrouch, 2005). For example, White college students reported higher prejudicial attitudes towards Arab Americans compared to any other racial ethnic groups (Bushman \& Bonacci, 2004). In Zogby’s 2002 poll of 505 Arab Americans, $40 \%$ of participants indicated that they knew someone who was discriminated against since the $9 / 11$ attacks. One in three participants reported that they experienced discrimination themselves and approximately $78 \%$ of individuals reported that there has been more profiling of Arab Americans since September 11 (Zogby, 2002). Arab Americans living in New York City reported increased feelings of fear and anxiety due to intensified hate crimes (Abu-Ras \& Abu-Bader, 2008). One female participating in a focus group encapsulated the feeling of many participants about the way that Americans perceive Arabs in the United States: "They look at us as enemies and not as American citizens. We became the ones blamed for any terrorists activities inside and outside the U.S" (Abu-Ras \& Abu-Bader, 2008, p. 224).

Recently, with attacks carried out by ISIS on numerous countries, discrimination targeting the Muslim and Arab community in the United States has been on the rise. The Council on American-Islamic Relations (CAIR), the nation's largest Muslim civil rights and advocacy organization, released a report indicating that they received more reports about acts of discrimination, intimidation, threats, and violence targeting American Muslims and Islamic institutions in the week following the terror attacks in Paris on November 13, 2015, than during 
any other limited time period since the 9/11 terror attacks (Naeem, 2015). CAIR attributes the increased acts of discrimination to the anti-Muslim rhetoric propagated by political leaders and presidential candidates. Arab Americans are met by an increase in these acts of prejudice, discrimination, and hostility and encounter these negative attitudes in their everyday lives (Disha, Cavendish, \& King, 2011; Howell \& Shyrock, 2003).

Nonetheless, information available about Arab Americans is limited and far behind compared to other ethnic minority groups, which is partly due to the government's decision to not recognize Arab Americans as a minority group (Ibish, 2001). As a result, many law enforcement offices do not consider Arab Americans a protected minority group, and choose not to record hate crimes committed against them (Ibish, 2001). This lack of recognition impedes the ability of researchers to raise scholarly awareness about the needs and experiences of Arab Americans (Ibish, 2001) and, therefore, requires the attention and investigation of increased research.

\section{Discrimination against and psychological well-being of Arab Americans}

Being exposed to discriminatory behavior has been recognized as a pervasive stressor in the lives of people of color (Garica Coll et al., 1996). Ethnic minorities tend to experience feelings of anger, hurt, bitterness, helplessness, hopelessness, and a desire to lash out when exposed to race-related stress (Wagner et al., 2011). These potential responses may lead to elevated levels of symptoms of depression and anxiety (Karlamangla, Zhou, Reuben, Greendale, \& Moore, 2006; Ogden, 2012). For example, among African American, Asian American, and Latin American high school students, perceived discrimination was significantly associated with decreased self-esteem and increased symptoms of depression (Greene, Way, \& Pahl, 2006). For African American women and men (Moradi \& Subich, 2003), White women (Corning, 2002), 
and lesbian, gay, and bisexual individuals (Waldo, 1999), reported experiences of discrimination were related to a greater level of psychological distress. An emotional response in result of exposure to discriminatory behavior characterized by a sense of helplessness, hopelessness, and anger may lead an individual to choose to manage these feelings by relying on a myriad of selfsoothers such as alcohol and other substances, which can lead to chronic health problems over time (Karlmangla et al., 2012).

Such discrimination appears to have caused psychological distress in Arab Americans as well (Amer, 2007). Arab Americans tend to experience similar responses to discrimination that other ethnic minority groups display such as anxiety, depression, and trauma-related disorders (McAuliffe, 2008). Middle Eastern immigrants who face immigration-related traumas, cultural differences in comparison to American life, the loss of extended family support if only a portion of the family has immigrated, and limited knowledge of the legal and health care systems in America, showed similar psychological distress (McAuliffe, 2008; Laffrey, Meleis, Lipson, Solomom, \& Omidan, 1989). Arab American youth who reported more discrimination tended to accept discriminatory treatment as part of life and experienced more anxiety than youth who reported few to no experiences of discrimination (Sirin \& Fine, 2007). A systematic review of literature on the health of Arab Americans in the U.S. stated that the most prevalent mental health concerns in this population were related to family dysfunction and feelings of depression, which appear to be associated with stress related to cultural adaptation and discrimination (ElSayed \& Galea, 2009). Experiences of perceived discrimination were related to lower levels of perceived control and linked to an overall lower sense of self-esteem and greater psychological distress in Arab Americans (Moradi \& Hassan, 2004). 
On the other hand, the link between perceived discrimination and psychological wellbeing (vs. psychological distress) has been explored with the Arab American population only minimally. Researchers have called for an increased amount of research on the study of the psychological well-being of individuals, as attending only to psychological distress leads to a gap in understanding an individual's overall health, quality of life, and resilience (Winefield, Hill, Taylor, \& Pilkington, 2012). Given the current social climate filled with stigmatization, prejudice, and discrimination against Arab Americans (Ibish, 2003), it is imperative to examine the association between psychological well-being (vs. psychological distress) and perceived discrimination in order to get a better overall picture of Arab American mental health.

\section{Ethnic Identity}

Even in the vast array of discrimination and prejudice, ethnic minorities demonstrate strength and resilience by enabling a combination of protective factors that allow them to prosper in society. Individuals use a variety of coping strategies and resources such as seeking out other ethnic minorities for support, matching their behaviors to that of the majority in an effort to assimilate, and some individuals may altogether choose to avoid situations that might expose them to the threat of discrimination (Phinney \& Chavira, 1995; Phinney, 1992; Crocker \& Major, 1989). Among others, ethnic identity is considered to be one of the most important psychological resources that an individual utilizes to demonstrate resilience against discrimination (Phinney, 2003) because it can serve as a source of strength and may influence the way in which an individual chooses to cope with discrimination (Chavira \& Phinney, 1991).

Ethnic identity has been depicted as a sense of belonging to an ethnic group, which is accompanied by a feeling of pride to be part of that ethnic group (Phinney, 2003). People who encompass an ethnic identity have a greater sense of understanding and self-awareness of what it 
means to be a minority in society. Such self-awareness may reduce an individual's chance of experiencing the negative impacts of discrimination (Phinney, 2003). The following section of this literature review will address the identity theories that influenced the conceptualization of ethnic identity and the impact of ethnic identity on the psychological health of Arab Americans.

\section{Identity and ethnic identity}

The development of identity is a crucial task that takes place during adolescence and serves as an ongoing frame of reference for adulthood (Josselson, 1994; Spencer, Swanson, \& Cunningham, 1991; Swanson, Spencer, \& Peterson, 1997). Identity development encompasses the ability to define oneself in terms of multiple social identities, such as gender and occupation, while attempting to achieve a coherent sense of self that includes the formation of an ethnic identity (Umaña-Taylor, Yazedjian, \& Bámaca-Gómez, 2004). Much of the development and research surrounding ethnic identity theories has been grounded in Tajfel's (1981) social identity theory and Erikson's (1968) theory of identity formation. Tajfel's social identity theory asserts that an individual develops a sense of identity through feelings of belonging to a particular group, with the accompanying component of an affective sense of group membership. Tajfel suggested that an individual's sense of self-esteem is linked to their sense of group belonging. If an individual holds positive thoughts about their group membership, they would, in turn, develop a positive self-esteem (Phinney, 1992; Phinney, Cantu, \& Kurtz; 1997).

Erikson's (1968) theory of identity formation describes the development of identity as a process of exploration and commitment. Through the process of exploration an individual arrives at a resolution about a component of their identity and decides whether to embed that component into their broader sense of self. An important note to mention is that Erikson did not claim that an individual's commitment to a component of their identity is always positive. Instead, Erikson 
focused on the process of identity development rather than the positive or negative thoughts an individual maintains about their group.

Marcia's (1980) operationalization of ethnic identity, based on Erikson's theory, allowed individuals to be classified into different identity statuses based on their degree of exploration and commitment. The four identity statuses are: diffuse, foreclosed, moratorium, and achieved. The statuses were used to determine whether an adolescent has committed to an identity or whether the adolescent was still searching for their identity. The diffuse status indicates that an adolescent made no attempt to explore or commit to an identity. If an adolescent blindly accepted the values given to them during childhood and committed to an identity, then the individual fell into the foreclosed status. Moratorium describes an adolescent that is still exploring their identity. Achieved status means the adolescent has explored and committed to an identity.

Building off the work of Marcia's (1980) operationalization, Tajfel's (1981) theory and Erikson's (1968) theory, Phinney (1989) developed a three-stage model for understanding minority ethnic identity. Noting the difficulty distinguishing between foreclosed and diffuse statuses in White, Asian, Hispanic, and Black adolescents, Phinney (1996) proposed three stages of ethnic identity development. The first stage is labeled 'unexamined ethnic identity' and is characterized by the lack of exploration of ethnicity (i.e., similar to foreclosure). It posits that an individual initially accepts the values of the majority culture, which includes negative views of their heritage group held by the majority group. The second stage is labeled 'ethnic identity search/moratorium' which is representative of an individual beginning to explore and create meaning for their ethnicity (i.e., similar to moratorium). An individual may have positive attitudes and high involvement with their own group and may hold anger toward Whites while empathizing with other minorities (Phinney, 1996). Ethnic identity achievement is the third and 
final stage and the ideal outcome in achieving an ethnic identity (i.e., similar to achieved status). It is characterized by a clear sense of one's ethnicity. During this final stage, the individual internalizes what their ethnicity means to them and comes to term with their group membership (Umaña-Taylor et al., 2004; Phinney, 1996). In order to assess these three stages, Phinney (1992) suggested that the dimensions of exploration, commitment, participation in cultural activities, and an adolescent's positive feelings towards their ethnic group should be considered. However, he also proposed the final stage of identity achievement would be determined by positive feelings attributed to an adolescent's ethnic group, not taking into account the exploration and commitment that were originally proposed as crucial identity dimensions by Erikson. Also, Erikson suggested an individual does not need to hold positive feelings towards their ethnic group in order to reach a point of identity achievement (Umaña-Taylor et al., 2004). Following Erikson's theory, an adolescent may reach identity achievement while holding negative thoughts about their group as long as they have explored and committed to an identity.

Noting this limitation in Phinney's (1996) conceptualization and assessment of ethnic identity, Umaña-Taylor et al., (2004) explored the identity statuses of diffuse, foreclosed, moratorium, and achievement alongside an additional dimension of positive or negative affirmation of one's ethnic groups in order to encapsulate adolescents who held negative views of their group and successfully achieved an ethnic identity. They provided a following example to demonstrate such a case. If two Filipino sisters both explore their ethnicity and feel confidently about what being Filipino means to them, they engaged in exploration and resolution. If one of the sisters feels very negatively about the Filipino culture and the other sister feels very positively about the Filipino culture, they have both undergone the same process but arrived at different conclusions. However, both sisters have achieved an ethnic identity. In sum, 
ethnic identity formation is composed of the following three components: the degree to which an individual has explored their ethnicity, the degree to which an individual has resolved what their ethnicity means to them, and the affect (positive or negative) that an individual associates with their resolution (Umaña-Taylor et al., 2004).

\section{Ethnic identity in Arab Americans}

Exploration of an Arab identity has been examined in association with experiences of acculturative stressors, the family context, and discrimination (Ajrouch, 2004; Britto \& Amer, 2007; Sirin \& Fine, 2007). Amer (2007) explored cultural identity patterns in Arab Muslim American young adults and discovered that participants fell into one of three cultural identity groups: high bicultural, moderate bicultural, and high Arab cultural. In this study, cultural identity referred to the degree to which each participant was influenced by both their heritage culture and the mainstream culture. Participants with stronger Arab identities were more likely to be married and/or cultivated stronger relationships with family members. Use of the Arabic language at home and exposure to Arabic TV was also closely linked to a strong Arab cultural identity (Amer, 2007). Findings aligned with previous studies which indicate that self-selecting a bicultural identity is common among ethnic minority adolescents, and it appears to be the most psychologically adaptive (Amer, 7002; Garcia Coll \& Magnuson, 1997; Rotherham-Borus, 1993; Phinney, Horenczyk, \& Liebkind, 2001).

Focus group interviews with Arab American adolescents explored the parameters adolescents use to define their identities and studied the boundaries that children of immigrants create in order to differentiate themselves from others. Ajrouch (2004) discovered a continuum of identity with the term "boater" at one end of the pole and "white" at the other end of the pole. The participants described the term "boater" as an individual who speaks Arabic more than 
English and as someone who has a noticeable accent when speaking English. On the other hand, a person referred to as "white" was seen as different from them and viewed as an American. Although Arab Americans are considered White on U.S. Census forms, much of the discussion revealed that the adolescents did not identify as "white" (Ajrouch, 2004). Southeast Asian and Arab participants crafted a hyphenated self when directed to design picture descriptions of their identity, such as Arab-American or Muslim-American. Participants revealed that they oftentimes try to create a balance and "live at the hyphen" (Sirin \& Fine, 2007). Although the Census Bureau considers them White, they are not treated as such. Therefore, Arab American adolescents feel the need to construct an identity that somehow encapsulates the opposing components (Howell \& Shyrock, 2003). The contradiction of classification as 'White' while 'Arab' has forced Arab Americans to negotiate their ethnic identity unlike most other ethnic minority groups (Howell \& Shyrock, 2003; Naber, 2000). In attempts to self-identify and negotiate their heritage culture and American culture, youth label themselves and one another in a multitude of ways.

\section{Ethnic identity and well-being}

Social psychological and developmental perspectives suggest that a strong positive ethnic identity contributes to the psychological well-being of individuals. Tajfel's (1981) Social Identity Theory asserts that ethnic identity strengthens an individual's self-esteem due to a positive sense of group membership. Self-esteem is often conceptualized as global feelings of self-worth, or general feelings of self-acceptance, worthiness, self-respect, and goodness (Rosenberg, 1965, 1979; Wylie, 1979). In order to achieve positive self-esteem, the individual needs to differentiate the group from a comparison out-group on a dimension deemed valuable (Tajfel, 1981). In-group identification provides an individual with resources and assets that motivate them to identify 
with their in-group in order to secure a positive sense of identity. Resources and assets provided by the in-group include a sense of security, belongingness, social support, and stability (Tajfel \& Turner, 1986).

Developmental models of ethnic identity posit that children who are exposed to negative stereotypes of their ethnic group may have conflicting or negative views about their own group (Phinney, 1989). In order to develop positive feelings towards their ethnic group, children need to be influenced by an ethnic community that provides positive context (Rosenthal \& Hrynevich, 1985; Liebkind \& Jasinskaja-Lathi, 2000). Phinney and colleagues (2001) found that adolescents classified as having marginalized identities, where the individual does not identify with either the ethnic group or the new culture, showed lower levels of psychological adaptation. Research supported the notion that an integrated identity, defined as simultaneous ethnic retention and adaptation to the new society, promotes the healthiest psychological adaptation (Phinney, Horenczyk, \& Liebkind, 2001).

Umaña-Taylor et al., (2004) suggested that for both ethnic minority and White adolescents, degrees of affirmation (i.e., positive feeling toward one's racial/ethnic group) and resolution (i.e., commitment) were positively related to self-esteem. On the other hand, exploration was positively related to self-esteem in ethnic minority adolescents only, not in White adolescents (Umaña-Taylor et al., 2004). This result suggests that all three dimensions of exploration, resolution, and affirmation are associated with self-esteem for ethnic minorities. However, the question as to whether an achieved ethnic identity enhances self-esteem, or whether a high self-esteem leads to ethnic identity achievement, remains unanswered (Phinney \& Chavira, 1992). 
Ethnic identity also was associated with other aspects of psychological well-being including happiness, positive affect, hope, and life satisfaction in Latino/as (e.g., Umaña-Taylor \& Updegraff, 2007), African Americans (e.g., Sellers, Caldwell, Schmeelk-Cone, \& Zimmerman, 2003), and Asian Americans (e.g., Lee \& Yoo, 2004).

\section{Ethnic identity and well-being in Arab Americans}

A limited number of research studies that has examined Arab American ethnic identity suggests that ethnic identity plays a similar positive role in Arab Americans. For example, stronger ethnic identity was related to lower psychological distress and increased positive psychological functioning in a sample of Arab American emerging adults (Ahmed, Kia-Keating, \& Tsai, 2011; Sheldon, Oliver, \& Balaghi, 2015). Specifically, the only hitherto study that examined all three ethnic identity dimensions showed that affirmation and a sense of positive belonging to their ethnic group and higher level of exploration was related to greater sense of self-acceptance, and commitment to ethnic identity was associated with a greater sense of meaningful life in this population (Sheldon et al., 2015).

\section{Ethnic identity as a protective factor against discrimination}

Even in the face of prejudice and discrimination ethnic minorities display a high degree of resilience. Sandler (2001) proposed that resources, which contribute to an individual's resilience, could protect against the effects of adverse experiences, such as discrimination and prejudice. As proposed by Crocker and Major's (1989) theory on self-protecting functions of external attributions, the more an individual identifies with a group that is discriminated against or devalued in current society, the more likely the individual will be able to use group-level selfprotective strategies to combat the negative impacts of discrimination. In applying this theory to ethnic minorities, the degree to which the person has identified with their ethnic group can serve 
as a protective factor by minimizing the negative impacts of discrimination. In other words, an individual's experiences of discrimination would not serve as a hindrance to their freedom to identify with their ethnicity, but it would enable self-protective strategies in times of perceived discrimination. Previous research with Latino/a Americans indicated that individuals with high ethnic identity had significantly higher self-esteem, as they used active coping strategies to deal with discrimination, compared to individuals with low ethnic identity who chose passive coping styles (Chavira \& Phinney, 1991). Similarly, African Americans, Japanese Americans, and Mexican Americans with high ethnic identity were less likely to use passive coping styles against discrimination, such as ignoring (Phinney \& Chavira, 1995).

\section{Ethnic identity as a protective factor against discrimination in Arab Americans}

For many Arab Americans, the days and months that followed the terror attacks on September 11, 2001 were filled with feelings of insecurity and vulnerability (AADC, 2002). However, the resilience of Arab Americans in such difficult times has prompted researchers to explore the factors that help them continue to prosper. The Arab American community in New York City reported turning to its religious institutions in times of emotional need to learn how to cope with increased stressors and to achieve a feeling of inner satisfaction (Abu-Ras \& AbuBader, 2008). Similarly, Ahmed and colleagues (2011) reported that the availability and access of cultural resources promoted psychological well-being in Arab American adolescents, and ethnic identity, religious coping, and religious support were negatively related to psychological distress. As an individual reported an increase in cultural resources, the individual was less likely to report high levels of depression and anxiety. In congruence with previous research findings, when an individual achieved an ethnic identity status and made the decision to claim group membership of the Arab culture, they were less likely to report experiences of discrimination 
(Willems, 2012). In sum, it appears that ethnic identity may serve as a protective factor for Arab Americans when facing adversity characterized by increased discrimination, prejudice, and hostility, although it has not been directly investigated as such in this population.

\section{Current Study}

The current study aimed to expand research on Arab Americans who have experienced a dramatic increase of discrimination since 9/11 and also recent ISIS-related terrorist attacks. Specifically, this study examined the impact of perceived discrimination on psychological wellbeing (vs. psychological distress) in Arab Americans. Much of the research conducted on discrimination against Arab Americans has been centered on its association with psychological distress (e.g., Sirin \& Fine, El-Sayed \& Galea, 2009). Such studies have shown that perceived discrimination is significantly related to psychological distress (Amer, 2007), including increased anxiety (Sirin \& Fine, 2007) and decreased self-esteem in Arab American individuals (Moradi \& Hassan, 2004). The current study intended to expand from upon the current body of research by examining the association between perceived discrimination and psychological well-being (vs. psychological distress), in order to obtain a broader picture of the impact discrimination has on an individual's psychological health. Based on the limited previous body of literature that demonstrated perceived discrimination was related to lower self-esteem in Arab Americans (Moradi \& Hassan, 2011) and decreased psychological functioning in other ethnic minority groups (Smith \& Silva, 2011), the current study proposed that perceived discrimination would be negatively related to psychological well-being in Arab Americans. Components of psychological well-being in this study included flourishing (i.e., individual's perceived level of success in areas of optimism, purpose, and relationships.), self-esteem, and satisfaction with life (Diener et al., 2009). They have been used as indicators of well-being in other ethnic studies, which allows for 
comparison of the current study results with the existing literature on other ethnic minority groups (Sheldon et al., 2015; Umaña-Taylor et al., 2004).

In addition, ethnic identity was investigated as a direct predictor of psychological wellbeing and also as a potential protective factor (i.e., moderator) against the negative influences of discrimination in Arab Americans. In studying ethnic identity, I used the most recent conceptualization that includes three dimensions of exploration, commitment, and affirmation of ethnic identity (Umaña-Taylor et al., 2004). This framework is consistent with the original identity theories (i.e., Marcia's operationalization of Erikson's [1968] theory and Tajfel's [1986] social identity theory), and complements the most widely used conceptualization by Phinney (1996) that did not consider the possibility of achieved identity with negative affirmation.

This recent conceptualization has been applied in Latino/a, Asian, and African Americans, but not in Arab Americans (Umaña-Taylor et al., 2004). The eight ethnic identity statuses can be derived by the combinations of the three dimensions: Diffuse positive, diffuse negative, foreclosed negative, foreclosed positive, moratorium negative, moratorium positive, achieved negative, and achieved positive. In studying ethnic identity in Arab Americans, I first explored whether the eight statuses are also identified in Arab Americans.

Then, whether ethnic identity dimensions predicted psychological well-being in this population was explored. Previous research has illustrated the potential of ethnic identity in promoting self-esteem in ethnic minorities in general (Umaña-Taylor et al., 2004) and promoting feelings of self-acceptance and a sense of a meaningful life in Arab American individuals (Sheldon et al., 2015). As ethnic identity increases, psychological distress has been reported to decrease in Arab Americans as well (Ahmed et al., 2011). Therefore, the current study predicted that high exploration, high resolution, and high affirmation would be positively associated with 
the psychological well-being components of flourishing, self-esteem, and satisfaction with life in Arab Americans.

Ethnic identity has been known to be a protective factor against the impact of discrimination in many ethnic minority groups (Chavira \& Phinney, 1991; Phinney \& Chavira, 1995). Research with Arab Americans also suggests that high ethnic identity is associated with less perceived discrimination, but it has not been directly examined as a protective factor against discrimination on psychological well-being. Thus, this study examined whether the ethnic identity dimensions of high exploration, high resolution, and high affirmation would serve as a protective factor, weakening the relationship between perceived discrimination and psychological well-being in Arab Americans.

In sum, this study examined (a) whether the eight identity statuses are identified in Arab Americans, (b) whether perceived discrimination predicts psychological well-being negatively, (c) whether ethnic identity predicts psychological well-being positively, and (d) whether ethnic identity moderates the impact of perceived discrimination on the psychological well-being in Arab Americans.

\section{Research questions and hypotheses}

Exploratory research question 1. Are the ethnic identity statuses previously identified through cluster analyses in White, Latino/a, Asian, and Black participants by Umaña-Taylor et al. (2004) replicated in a community sample of Arab Americans?

Hypothesis 1. To the best of our knowledge, there have not been any research studies that focused solely on Arab Americans to identify ethnic identity clusters. Umaña-Taylor et al. (2004) used a k-mean cluster analysis to categorize participants, classified by race (White, Asian, Latino/a, etc.), and place individuals into ethnic identity clusters determined by cut-off scores. 
The question remains open as to whether a sample of Arab Americans will fall into any of the following ethnic identity clusters identified by Umaña-Taylor et al. (2004): Diffuse positive, diffuse negative, foreclosed negative, foreclosed positive, moratorium negative, moratorium positive, achieved negative, and achieved positive.

Research question 1. Does perceived ethnic discrimination predict psychological wellbeing (satisfaction with life, flourishing, and self-esteem) in Arab Americans?

Hypothesis 1. Perceived ethnic discrimination would be negatively related to satisfaction with life, flourishing, and self-esteem in Arab Americans.

Research question 2. Do ethnic identity statuses (exploration, resolution, affirmation) predict psychological well-being (satisfaction with life, flourishing, self-esteem) in Arab Americans?

Hypothesis 2. Exploration, resolution, and affirmation dimensions (achieved positive, moratorium positive, foreclosed positive) of ethnic identity would predict life satisfaction, flourishing, and self-esteem positively.

Research question 3. Do any of the ethnic identity statuses (exploration, resolution, affirmation) moderate the relationship between perceived ethnic discrimination and components of psychological well-being (satisfaction with life, flourishing, self-esteem)?

Hypothesis 3. High exploration, high resolution, and high affirmation (achieved positive status) would weaken the relationship between perceived ethnic discrimination and satisfaction with life, flourishing, and self-esteem. 


\section{CHAPTER III: METHODOLOGY \\ Participants}

\section{Eligibility}

Participants were selected based on the following criteria: a) self-identified as Arab American; b) self-identified as proficient in English; c) living in the United States; d) age 18 or over. Participants were born either in an Arab country or the United States and affiliated with any religion. Participants also had to be at least 18 years old in order to consent to participate in the study on their own.

\section{Sample size}

Based on a review of the literature, a medium effect size was deemed most appropriate for the current study (Awad, 2010; Ahmed et al., 2011; Sheldon et al, 2015). A minimum sample size of 164 participants was required to meet the standard for a medium effect size. The alpha size was set to .05 and the power was determined to be .80 . A total of 156 participants made up the current sample size and did not meet the minimum participant requirement.

\section{Recruiting}

Individuals were recruited from mosques, Arab and/or Muslim organizations, and universities in the Midwest region of the United States. The recruitment process of the nonrandom convenience sample began by gathering a list of contact information for Arab and/or Muslim organizations. A snowball method was also employed, and participants were asked to disseminate information about the survey to others who met the criteria for participation.

Religious leaders from mosques were contacted through e-mail describing the purpose of the study and requesting that they distribute the survey link to members of the mosque via email. The following mosques have high concentrations of Arab Americans and were contacted 
directly: (1) Islamic Society of Milwaukee in Wisconsin, (2) Dar Al-Salam Foundation in Illinois, (3) Orland Park Prayer Center, (4) the Islamic Center of Bloomington-Normal in Illinois, (5) Islamic Center of Peoria, (6) Mosque Foundation in Bridgeview, Illinois.

Leaders of student organizations such as Muslim Student Association, Arab Student Association, and Students for Justice in Palestine in Midwestern universities were contacted through Facebook and organization websites. The following organizations, not affiliated with universities, were also contacted: (1) National Students for Justice in Palestine, (2) Arab and Muslim Women Research and Resource Institute, (3) American Muslims for Palestine of Milwaukee and Chicago, (4) Milwaukee Muslim Women Resource Center.

A direct URL link to the online survey was provided in the e-mail, as well as the researcher's e-mail for further inquiries. Universities, organizations, and religious centers in Illinois, Michigan, and Wisconsin were the locations targeted due to the researcher's connections and the high concentration of Arab Americans living in the three states (AAI, 2012). According the AAI, more than two-thirds of Arab Americans live in just ten states, with two of the ten states being Illinois and Michigan. Participants were also recruited from Wisconsin, Illinois, and Michigan due to the researcher's connections to cultural and religious institutions in the Midwest.

\section{Participant characteristics}

A total of 232 participants were recruited for the current study. Of those 232 participants, 30 met eligibility requirements but did not complete any part of the online survey, and 8 failed to meet all of the eligibility requirements and could not participate in the survey. A total of 15 participants completed the socio-demographic questionnaire and none of the other measures. Twenty-three participants did not complete the perceived discrimination measure and of those 23 
participants, 18 participants did not complete at least one other full measure. After accounting for participants who did not complete all the questionnaires and did not meet the inclusion criteria, 156 participants remained and were used for data analyses.

Of the 156 participants, 99 identified as female (63\%), and 57 identified as male (37\%). Participant age ranged from 18 to 65 years old, with the mean age of $27.3(S D=8.2)$. The majority of participants were Muslim at 77\% $(n=120)$, whereas $13 \%$ were Christian $(n=21)$. The remaining respondents either indicated not belonging to a specific religion, or identified as spiritual. Participants came from 27 states across the United States. The largest number of respondents came from Wisconsin $(31 \%, n=49)$, followed by California $(11 \%, n=17)$, and Illinois $(9 \%, n=14)$, with the remaining participants' coming from other states.

The largest group of respondents indicated that they were employed for wages, whereas the next largest group was students (See Table 1).

Table 1

Frequency Distribution - Employment status

\begin{tabular}{lcc}
\hline & $n$ & $\%$ \\
\hline Employed for wages & 76 & 49 \\
Student & 46 & 29 \\
Self-employed & 17 & 11 \\
Out of work and looking for work & 3 & 2 \\
Homemaker & 6 & 4 \\
Out of work and not looking & 3 & 2 \\
\hline
\end{tabular}


A large majority of respondents reported speaking English primarily at home $(64 \%, n=$ 100). The next largest group indicated speaking Arabic primarily in the home $(26 \%, n=41)$. The remaining respondents indicated speaking both English and Arabic in the home $(8 \%, n=12)$, and the remaining participants' indicated other languages. The mean number of visits to the Arab world was 5.94, with number of visits ranging from 0 to 47 visits. Of the 156 participants, 35 $(22 \%)$ of the respondents indicated they were first generation immigrants. The remaining participants were asked to leave the question blank if born in the United States, indicating that $121(77 \%)$ respondents identified as second generation immigrants.

Participants were asked to select family country of origin, defined as the country with which the respondent, and their immediate family members identify with. A large majority of the participants selected Palestine as their family country of origin $(60 \%, n=94)$. The next largest subgroup for family country of origin was Lebanon $(7 \%, n=11)$, followed by Syria $(6 \%, n=$ 10). The remainder of participants selected a variety of other countries from the Middle East.

The largest majority of respondents obtained a bachelor's degree $(46 \%, n=72)$, and the next largest subgroup completed some college, but had no degree yet $(29 \%, n=46)$. The remaining respondents had master's degrees $(12 \%, n=19)$, doctoral degrees $(7 \%, n=11)$, five participants completed an associate's degree (3\%) and two completed a high school degree (1\%). In terms of socioeconomic status, a majority of the participants' indicated higher income, rather than a lower income status (see Table 2). 
Table 2

Frequency Distribution - Socioeconomic status

\begin{tabular}{lcc}
\hline & $n$ & $\%$ \\
\hline$\$ 100,000$ or more & 35 & 22 \\
$\$ 75,000-99,000$ & 14 & 9 \\
$\$ 50,000-74,999$ & 26 & 17 \\
$\$ 35,000-49,999$ & 15 & 9.6 \\
$\$ 20,000-34,999$ & 18 & 11 \\
Less than $\$ 20,000$ & 13 & 8.3 \\
\hline
\end{tabular}

\section{Instruments}

The survey consisted of: 1) socio-demographic questionnaire, 2) the Ethnic Identity Scale (Umaña-Taylor et al., 2004), 3) Flourishing Scale (Deiner et al., 2009), 4) Satisfaction with Life Scale (Diener, Emmons, Larsen \& Griffin, 1985), 5) the Rosenberg Self-esteem Scale (Rosenberg, 1965), and 6) the Schedule of Racist Events - Arab American Version (Landrine \& Klonoff, 1996; Moradi and Hassan, 2004).

\section{Socio-demographic questionnaire}

The socio-demographic questionnaire captured descriptive information about the participants that the other measures did not address and also served to confirm the eligibility of the participant for taking part in the study. Participants were asked about demographic location, age, education level, religious affiliation, and occupation. Questions also focused on time lived in the United States, family country of origin, frequency of trips to the Arab world, and further indicators of immigrant generational status such as time lived in an Arab country. 


\section{Ethnic identity measures}

Ethnic Identity Scale. The EIS is a 46-item measure designed to examine a participant's ethnic identity and three distinct aspects of ethnic identity: a) exploration, b) resolution, and c) affirmation (Umaña-Taylor et al., 2004). The exploration subscale is made up of 23 items (e.g., "I have participated in activities that have exposed me to my ethnicity"). The resolution subscale consists of 13 items (e.g., "I know what my ethnicity means to me"). The affirmation subscale includes 10 items (e.g., "If I could choose, I would prefer to be of a different ethnicity"). Items were scored on a 4-point Likert scale with 1 being does not describe me at all and 4 being describes me very well. Responses were coded as that higher scores of each subscale indicate greater degrees of exploration, resolution, and affirmation. Coefficient alphas for scores from the exploration, affirmation, and resolution subscales were high at .91, .86, and .92 , respectively. Evidence for construct validity was demonstrated for the three subscales (i.e., exploration, affirmation, and resolution). Correlations among the subscales, a measure of self-esteem, and a measure of familial ethnic socialization were examined for majority group members (i.e., Whites) and ethnic minority group members. Exploration and resolution subscales were positively associated with self-esteem and familial ethnic socialization in ethnic minority members (Umaña-Taylor et al., 2004). There was a significant relation between exploration and resolution subscales and familial ethnic socialization but not for self-esteem in majority group members. For both groups, scores on the affirmation subscale were not significantly correlated with self-esteem or familial ethnic socialization (Umaña-Taylor et al., 2004). For the present study, Cronbach's alpha was .73 for exploration, .84 for resolution, and .82 for affirmation and demonstrated good reliability. 


\section{Psychological well-being measures}

Flourishing Scale. The FS is a brief, 8-item measure of respondents' self-perceived success in areas of optimism, purpose, self-esteem, and relationships (Deiner et al., 2009). Items were scored from a scale with a range from $1=$ strongly disagree to $7=$ strongly agree, with the midpoint of 4= neither agree not disagree. An example statement from the scale is "I lead a purposeful and meaningful life." The scale provides a single psychological well-being score with the possible range of scores from 8 to 56 . Convergent validity was demonstrated with correlations among other measures of subjective well-being including the Satisfaction with Life Scale (Diener, Emmons, Larsen \& Griffin, 1985) and Fordyce's (1988) single item measure of happiness. In the present study, PFS was strongly positively correlated with the Satisfaction with Life Scale (.73). Scores on the PFS demonstrated good reliability with a Cronbach alpha of .87.

Satisfaction with Life Scale. The SWLS is a brief, 5-item scale that measures global cognitive judgments of a respondents' satisfaction with their life (Diener, Emmons, Larsen \& Griffin, 1985). The first three items focused on the person's current life, and the last two items focused on how one's life has been previously, up until the present. The scale of the measure ranges from $1=$ strongly disagree to $7=$ strongly agree, with the midpoint as $4=$ neither agree nor disagree. An example of a statement that measures the person's current life is, "In most ways, my life is close to my ideal." An example of an item that measures one's previous life is, "If I could live my life over, I would change almost nothing." A total score was provided with 35 being the highest score possible and 5 being the lowest score possible. A higher score indicates greater satisfaction with life. Convergent validity was demonstrated with correlations among other measures of subjective well-being such as Bradburn Positive Affect Scale (Diener et al., 1985). The Cronbach's alpha coefficient was reported to be .68 . Test-retest yielded an average 
coefficient alpha of .83 . In the present study, the instrument demonstrated good reliability with an alpha of .86 .

Rosenberg Self-Esteem Scale. The Rosenberg Self-Esteem Scale (RSES) is a widely used self-report measure for evaluating an individual's self-esteem (Rosenberg, 1965). It is a 10item instrument that measures global self-worth through positive and negative feelings about the self. Respondents were asked to answer each item to indicate how strongly they feel about each statement using a 4-point Likert scale ranging from strongly agree to strongly disagree. An example item from the scale is "I feel that I'm a person of worth, at least on an equal plane with others." After reverse scoring specified items and an average for all 10 items, higher scores indicate higher self-esteem. Convergent, construct, and criterion validity have also been demonstrated for the measure. Correlations between the Single-Item Self-Esteem Scale and the Rosenberg Self-Esteem scale ranged from .72 to .76 (Robins, Hendin, \&, Tzesniweksi, 2001). Additionally, the RSES was significantly inversely correlated with depression with $r=-.73$. Pearson correlation coefficients also indicated that the RSES significantly correlated with 5 measures of maladaptive eating attitudes and behaviors in the expected direction (Griffiths et al., 1999). For the current study, the Cronbach alpha was .78, demonstrating good reliability.

\section{Perceived discrimination measure}

Schedule of Racist Events: Arab American version. The Schedule of Racist Events Modified for Use with Arab American persons (SRE-AA) was used to assess perceived ethnic discrimination. Moradi and Hassan (2004) formed the Arab American version of the SRE that was originally created by Landrine and Klonoff (1996) and used with African Americans. The SRE demonstrated excellent internal consistency (.96) with African Americans. The SRE-AA is a 17-item measure that assesses participants' experiences with racism. Moradi and Hassan 
(2004) found sufficient reliability for use of the SRE with Arab Americans age 18 and up with an alpha of .94. For the present study, each question was answered once for experiences in the past year. Respondents were asked to rate each item on a 6-point Likert-type scale from 1=not at all to $6=$ extremely. Sample items from the measure include: "How many times have you been treated unfairly by your employers, bosses and supervisors because of your Arab background," and "How many times have you been called a racist name like terrorist, towel head, foreigner or other names?" The current study rendered one score for experiences with racism in the past year. The Cronbach alpha was .92, demonstrating that the instrument had good reliability for the present study.

\section{Procedures}

An online-hosted survey was utilized to gather data from participants across many states in the Untied States Midwest. Potential participants were sent an e-mail describing the purpose of the research study and participation requirements. The e-mail asked readers who met the participation requirements to take part in the online survey. A direct URL to the survey was listed towards the bottom of the e-mail with an option to contact the researcher with any questions.

Once the participants connected to the online survey website, they were prompted with an informed consent document that detailed the objective of the study. For those who agreed to participate in the survey, they selected a button indicating they have read the consent information and were willing to participate before moving forward.

After the informed consent page, participants were first presented with a sociodemographic questionnaire. Once the socio-demographic questionnaire was completed, the following five measures were administered: Ethnic Identity Scale (EIS), Multidimensional 
Model of Arab Identity (MIAI), Flourishing Scale (FS), Satisfaction with Life Scale (SWLS), Rosenberg Self-esteem Scale, and Schedule of Racist Events - Arab American Version (SREAA).

\section{Data Analysis Plan}

To answer research question 1: Are the ethnic identity statuses previously identified through cluster analyses in White, Latino, Asian, and Black participants by Umaña-Taylor et al. (2004) replicated in a community sample of Arab Americans? Hierarchal cluster analysis was conducted to identify cluster patterns with use of the EIS subscale scores (exploration, commitment, and affirmation). Additionally, we repeated the k-mean cluster analysis done by Umaña-Taylor et al. (2004) as a supplementary analysis.

To test the three hypotheses: (a) perceived ethnic discrimination would predict psychological well-being negatively, (b) ethnic identity would predict psychological well-being positively, and (c) ethnic identity would moderate the relationship between perceived discrimination and psychological well-being, three multiple moderated regression analyses were conducted with self-esteem, flourishing, and satisfaction of life as dependent variables, respectively. All of the study variables were standardized and $z$-scores were used. The standardized variable scores were used to create the interaction terms. Perceived discrimination was entered in step 1 , the three ethnic identity dimensions in step 2 , and the interaction terms between discrimination and ethnic identity dimensions in step 3 . 


\section{CHAPTER IV: RESULTS}

The purpose of this study was to examine (a) whether perceived discrimination and ethnic identity dimensions predicted psychological well-being and (b) whether ethnic identity dimensions served as a buffer against the detrimental effect of perceived discrimination on psychological well-being among Arab Americans. Ethnic identity clusters were also identified for the current sample of Arab Americans.

\section{Description of Study Variables}

Descriptive statistics of the study variables, three dimensions of ethnic identity (i.e., exploration, resolution, and affirmation), perceived discrimination, and psychological well-being variables (i.e., self esteem, flourishing, and satisfaction with life) are presented in Table 3. 
Table 3

Means, Standard Deviations, Range of Study Variables

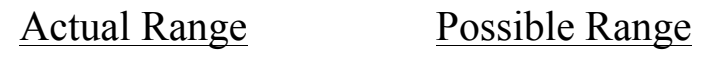

Variable $\quad M \quad S D$ Minimum Maximum Minimum Maximum

Ethnic Identity

Exploration

Resolution

22.93

$4.78 \quad 9$

$\begin{array}{lll}13.96 & 2.37 & 7\end{array}$

28

16

Affirmation

22.28

$2.92 \quad 10$

24

16

24

Perceived Ethnic

Discrimination

$\begin{array}{lll}35.37 & 13.17 & 17\end{array}$

81

17

102

Self-esteem

3.36

.43

1.5

4.0

1

4

Flourishing

47.13

$6.70 \quad 25$

56

8

56

Satisfaction with

Life

26.07

6.139

35

9

35

The skewness and kurtosis of the variable scores were examined for their normality. Affirmation scores were negatively skewed (-1.9) with high kurtosis (3.4). The absolute values of skewness and kurtosis statistics for the other variables were lower than 2. Participants' ethnic identity was measured through the dimensions of exploration, resolution, and affirmation. Independent sample $t$-tests were used to compare the means of the current study's ethnic identity dimensions to Umaña-Taylor's et al. (2004) findings with a sample of university students. On the exploration subscale, the current sample participants $(M=22.93, S D=4.78)$ scored significantly higher than the previous sample $(M=20.8, S D=4.8), t(318)=-4.39 p<.001$. On the resolution 
subscale, the current sample $(M=13.99, S D=2.38)$ also scored significantly higher than the previous sample $(M=11.7, S D=2.9), t(374)=-8.84, p<.001$. However, there was no significant difference across means from the current sample's degree of affirmation ( $M=22.28$, $S D=2.87)$ and Umaña-Taylor et al., (2004) sample $(M=22.7, S D=2.4), t(269)=1.54, p=.13$ In summary, the current sample demonstrated higher degrees of exploration and resolution in comparison to the results found by Umaña-Taylor and colleagues (2004).

Norms based on populations in the United States were provided for the well-being measures of flourishing and satisfaction with life. The mean score of 47.13 for flourishing fell into the norm range of 44-48 indicating an average level of flourishing after all of the measured items were summed (Diener \& Biswas-Diener, 2008). The norm provided for the satisfaction with life scale fell within the range of 23 to 28 , indicating slightly satisfied to satisfied (Pavot \& Diener, 1993). The mean score for the current sample fell within the norm for satisfaction with life at 26.07, indicating that participants responded within the norm range. For self-esteem, an independent samples t-test was conducted to compare mean differences between the current sample $(M=3.38, S D=.41)$ and Moradi and Hasan's (2004) sample of Arab Americans ( $M=$ $3.49, S D=.57)$. There was no significant mean difference between samples for self-esteem, $t$ $(236.6)=0.38, p=.70$. With regard to perceived ethnic discrimination, participants answered each item based on experiences from the past year $(M=35.16, S D=13.01)$. In a previous study using the same measure of perceived discrimination, Arab American participants reported a mean total of $50.37(S D=16.93)$ racist events (Willems, 2012). An independent sample t-test was conducted to determine whether mean differences existed between the current study and Willem's (2012). A significant difference did emerge between the number of racist events reported between both samples, $t(173)=7.52, p<.001$, and indicated that perceived 
discrimination for the present sample was lower than Willem's (2012) sample. In summary, the Arab American sample of the current study showed average or similar levels of scores on study variables in comparison to the norms or previous research samples.

Table 4

Intercorrelations among Ethnic Identity Dimensions and Predictor Variables

\begin{tabular}{lccccccc}
\hline Measure & 1 & 2 & 3 & 4 & 5 & 6 & 7 \\
\hline 1. Exploration & - & & & & & & \\
2. Resolution & $.544^{* *}$ & - & & & & & \\
3. Affirmation & $.478^{* *}$ & $.481^{* *}$ & - & & & & \\
4. Discrimination & -.090 & -.156 & $-.361^{* *}$ & - & & & \\
5. Self-esteem & $.221^{* *}$ & $.345^{* *}$ & $.387^{* *}$ & $-.258^{* *}$ & - & & \\
6. Flourishing & $.386^{* *}$ & $.544^{* *}$ & $.588^{* *}$ & $-.425^{* *}$ & $.655^{* *}$ & - & \\
7. Life Satisfaction & $.209^{*}$ & $.390^{* *}$ & $.338^{* *}$ & $-.220^{* *}$ & $.562^{* *}$ & $.709^{* *}$ & - \\
\hline
\end{tabular}

${ }^{*} p<.05, * * p<.01$

Scores of the variables were correlated significantly with one another in the expected directions with some exceptions (see Table 4). Perceived discrimination was negatively related to self-esteem, flourishing, and satisfaction with life. Ethnic identity exploration and resolution were not significantly related to perceived discrimination. However, affirmation was significantly negatively related to perceived discrimination. All of the ethnic identity dimensions were positively related to one another. Self-esteem was positively correlated with flourishing, 
and satisfaction with life. Flourishing was positively correlated with satisfaction with life. All the ethnic identity dimensions were significantly associated with all the three components of psychological well-being (self-esteem, flourishing, and satisfaction with life), except for exploration not being associated with self-esteem. Exploration was positively associated with flourishing and life satisfaction. Resolution and affirmation were both positively related to selfesteem, flourishing, and satisfaction with life.

\section{Research Question \& Hypotheses Testing}

The first exploratory research question sought to determine whether ethnic identity statuses previously identified among White, Latino/a, Asian, and Black participants by UmañaTaylor et al. (2004) could be replicated in a sample of Arab Americans. Cluster analyses were conducted to address this research question. Hypotheses 2 through 4 predicted that discrimination would negatively predict well-being, the ethnic identity dimensions would positively predict well-being, and high ethnic identity would serve as a moderator between discrimination and well-being. These three research hypotheses were tested using three moderated regression analyses with the three psychological well-being variables as a dependent variable, respectively. The summed scores of perceived discrimination, flourishing, satisfaction with life and the average score for self-esteem were centered and standardized for the analyses. Results were presented by each outcome variable (self-esteem, flourishing, satisfaction with life).

\section{Exploratory research question 1}

To the best of my knowledge, there have not been any research studies that focused solely on Arab Americans to identify ethnic identity clusters. One study conducted by UmañaTaylor et al. (2004) used a $k$-mean cluster analysis to categorize participants, classified by race (White, Asian, Latino/a, etc.), and placed individuals into 8 ethnic identity clusters (i.e., $2 \times 2 \times 2$ 
determined by high vs. low scores on each of the three ethnic identity dimensions). The question remains open as to whether a sample of Arab Americans would fall into any of the following ethnic identity clusters identified by Umaña-Taylor et al. (2004): Diffuse positive, diffuse negative, foreclosed negative, foreclosed positive, moratorium negative, moratorium positive, achieved negative, and achieved positive. Thus, a k-mean cluster analysis was conducted to examine whether Umaña-Taylor's results were replicated. However, it is not clear whether all the eight clusters truly exist, given that the three ethnic dimensions are not orthogonal but were significantly correlated. Thus, a hierarchal cluster analysis was also conducted to identify ethnic identity statuses within the sample using the dimensions of exploration, resolution, and affirmation as they emerge, rather than forcing the conceptual 8 clusters.

First, a $k$-mean cluster analysis was conducted to arrange cluster membership to eight groups in order to follow the ethnic identity typology proposed by Umaña-Taylor and colleagues (2004). The centroids, or mean scores of the dimensions used as clustering variables, were used to assign participants to one cluster type. A total of 147 participants were placed into one of eight cluster memberships presented in Table 5. In an attempt to label the eight clusters, comparison of mean scores for each cluster dimension were used to differentiate whether a dimension was labeled high or low. Once the high/low status of the cluster dimensions was determined, the cluster was given a name to reflect the dimensions' scores. Three of the eight clusters reflected low exploration, low resolution, and low affirmation. In using Umaña-Taylor and colleagues' (2004) ethnic identity typology, all three of the clusters were labeled Diffuse Negative. In conclusion, it appears the eight clusters found by Umaña-Taylor and colleagues (2004) were not replicated in the current community sample of Arab Americans. 


\section{Table 5}

Frequency Distribution: Eight ethnic identity clusters

\begin{tabular}{lcccc}
\hline Cluster \# & Female & Male & $n$ & $\%$ \\
\hline 1 & 2 & - & 2 & 1 \\
2 & 5 & - & 5 & 3 \\
3 & 13 & 14 & 27 & 18 \\
4 & 53 & 15 & 68 & 46 \\
5 & 6 & 9 & 15 & 10 \\
6 & 2 & 5 & 7 & 5 \\
7 & 4 & 2 & 6 & 4 \\
8 & 10 & 7 & 17 & 11 \\
\hline
\end{tabular}

Next, a hierarchal cluster analysis was conducted in order to see which cluster groupings would emerge naturally. For the hierarchical cluster analysis, first scores from the three ethnic identity dimensions were standardized. Next, the standardized scores were used as the clustering variables in the hierarchal cluster analysis. Euclidian distance scores and Ward's linkage method were utilized. Results of the cluster analysis supported a 4-cluster solution due to the $22 \%$ change in the algorithm coefficients from stage 144 to 143 in the algorithm schedule.

An analysis of variance (ANOVA) analysis was performed to examine the mean differences on the ethnic identity dimension scores across the 4 clusters identified. The ANOVA yielded significant results for all three ethnic identity dimensions, indicating that the mean differences among clusters were statistically significant $(p<.001)$. Homogeneity of variance (Levene's test) was violated for the exploration dimension $(p<.05)$, but was not violated for the dimensions of resolution and affirmation. To offset the violation of homogeneity of variance for exploration, Welch's test was utilized for exploration, $F(3,34.07)=82.24, p<.001$, for resolution, $F(3,28.82)=114.91, p<.001$, and for affirmation, $F(3,30.96)=46.44, p<.001$. 
The four-cluster solution was interpreted, and clusters were named based on the UmañaTaylor and colleagues (2004) ethnic identity typology and mean difference comparisons among the clusters identified by the hierarchal cluster analysis. The first cluster was characterized by high exploration, high resolution, and high affirmation $(n=91,62 \%, 66$ women and 25 men). Therefore, it seems that the first cluster best represents the Achieved Positive ethnic identity status where an individual has made a commitment to their identity and feels positively towards the Arab culture. The second cluster was characterized by low exploration, low resolution, and high affirmation ( $n=13,9 \%, 5$ women and 8 men). This cluster seems to best represent the ethnic identity status of Diffuse Positive, which indicates that an individual has neither explored nor committed to their Arab identity but still holds positive feelings towards the Arab American identity. The third cluster was characterized by high exploration, low resolution, and high affirmation ( $n=26,18 \%, 14$ women and $12 \mathrm{men})$. The third cluster appears to be reflective of the Moratorium Positive ethnic identity status. An individual with this identity status is assumed to have explored his or her Arab identity and feels positively about being Arab but has not yet committed to an identity. Lastly, the fourth cluster was characterized by low exploration, low resolution, and low affirmation ( $n=17,11 \%, 10$ women and 7 men). The fourth cluster seems to best fit the Diffuse Negative ethnic identity status, which represents an individual who has not taken the time to explore what the Arab culture means to him/herself, has not commit to an identity, and feels negatively towards being Arab (see Figure 1). 
Figure 1

Ethnic Identity Statuses identified through cluster analysis

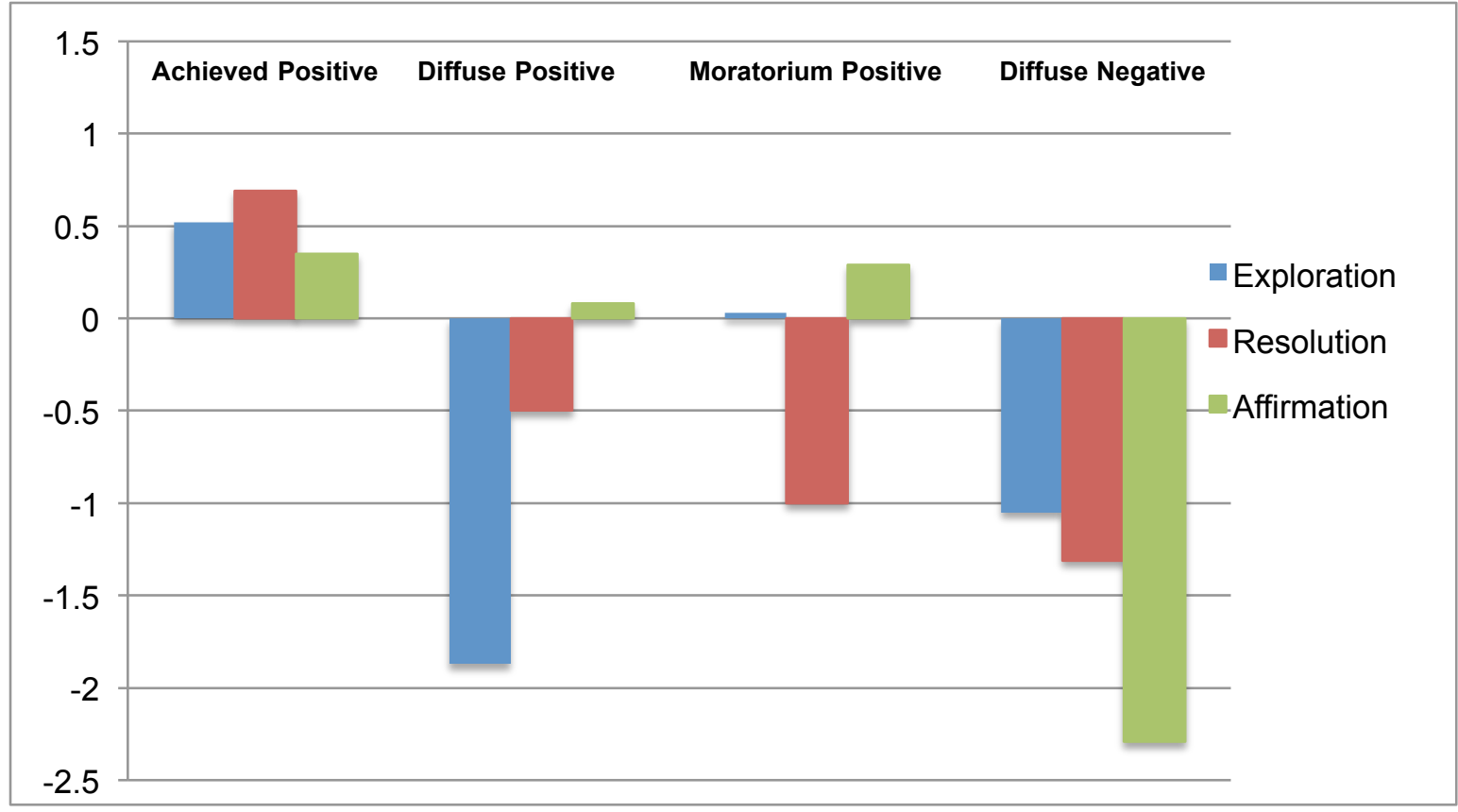

Figure 1. Scores above "0" indicate high endorsement of ethnic identity dimension. Scores below " 0 " indicate low endorsement of ethnic identity dimension.

Then, the following hypotheses were tested.

Hypothesis 1. Perceived ethnic discrimination would predict self-esteem, flourishing, and satisfaction negatively among Arab Americans.

Hypothesis 2. Exploration, resolution, and affirmation dimensions of ethnic identity would predict self-esteem, flourishing, and life satisfaction positively among Arab Americans.

Hypothesis 3. High exploration, high resolution, and high affirmation (achieved positive status) would weaken the relationship between perceived ethnic discrimination and self-esteem, flourishing, and life satisfaction among Arab Americans. 
Exploration, resolution, and affirmation served as predictors and potential moderators. Perceived discrimination was entered in Step 1, ethnic identity dimensions were entered in Step 2 , and interaction terms between perceived discrimination and ethnic identity dimensions were entered in Step 3.

\section{Self-esteem}

In Step 1, results showed that perceived discrimination accounted for $5 \%$ of the variance in self-esteem, $F(1,136)=7.90, p<.05, \Delta R^{2}=.05$ (see Table 6). In Step 2, results depicted that perceived discrimination and ethnic identity dimensions accounted for $17 \%$ of the variance in self-esteem, $F(3,133)=6.57, p<.001, \Delta R^{2}=.12$. In Step 3, only affirmation predicted selfesteem significantly; there were no significant interaction effects between ethnic identity dimensions and perceived discrimination on self-esteem, $F(3,130)=1.47, p=.22, \Delta R^{2}=.03$. 
Table 6

Moderated Regression Analysis on Self-esteem

\begin{tabular}{|c|c|c|c|c|c|}
\hline Variable & $\mathrm{B}$ & $\mathrm{SE}$ & $\beta$ & $R^{2}$ & $\Delta R^{2}$ \\
\hline Step 1 & & & & .055 & .055 \\
\hline Discrimination & -.241 & .086 & $-.234 *$ & & \\
\hline Step 2 & & & & .177 & .122 \\
\hline Discrimination & -.131 & .087 & -.127 & & \\
\hline Exploration & -.030 & .098 & -.029 & & \\
\hline Resolution & .250 & .106 & $.225^{*}$ & & \\
\hline Affirmation & .233 & .105 & $.219 *$ & & \\
\hline Step 3 & & & & .204 & .027 \\
\hline Discrimination & -.122 & .089 & -.119 & & \\
\hline Exploration & -.048 & .100 & -.046 & & \\
\hline Resolution & .282 & .107 & $.254^{*}$ & & \\
\hline Affirmation & .348 & .121 & $.327 *$ & & \\
\hline Discrimination $\mathrm{x}$ Exploration & .078 & .124 & .069 & & \\
\hline Discrimination $\mathrm{x}$ Resolution & -.119 & .107 & -.121 & & \\
\hline Discrimination $\mathrm{x}$ Affirmation & -.117 & .091 & -.149 & & \\
\hline
\end{tabular}




\section{Flourishing}

In Step 1, results showed that perceived discrimination accounted for $12 \%$ of the variance in flourishing, $F(1,134)=18.88, p<.001, \Delta R^{2}=.12$ (see Table 7). In Step 2, results revealed that the equation accounted for $42 \%$ of the variance in flourishing, $F(3,131)=22.50, p$ $<.001, \Delta R^{2}=.29$. The Step 3 equation accounted for $45 \%$ of the variance in flourishing, $F$ $(3,128)=2.41, p<.05, \Delta R^{2}=.03$. To determine the nature of the interaction effect, the significant interaction was probed by PROCESS (Hayes, 2012). Participants who were labeled with low affirmation fell under one standard deviation of the mean, and those labeled with high affirmation scored one standard deviation above the mean. For participants with high ethnic identity affirmation, perceived discrimination was not significantly related to flourishing, $b=$ $.099, S E=.103, t(140)=-.967, p=.33$. However, for those with low ethnic identity affirmation relationship, perceived discrimination was significantly negatively related to flourishing, $b=$ $.368, S E=.088, t(140)=-4.18, p<.001$ (see Figure 2). Therefore, it appears that high ethnic identity affirmation buffered the negative impacts of perceived discrimination on flourishing. 
Figure 2

Ethnic Identity Affirmation as a Moderator of the relationship between Perceived Discrimination and Flourishing

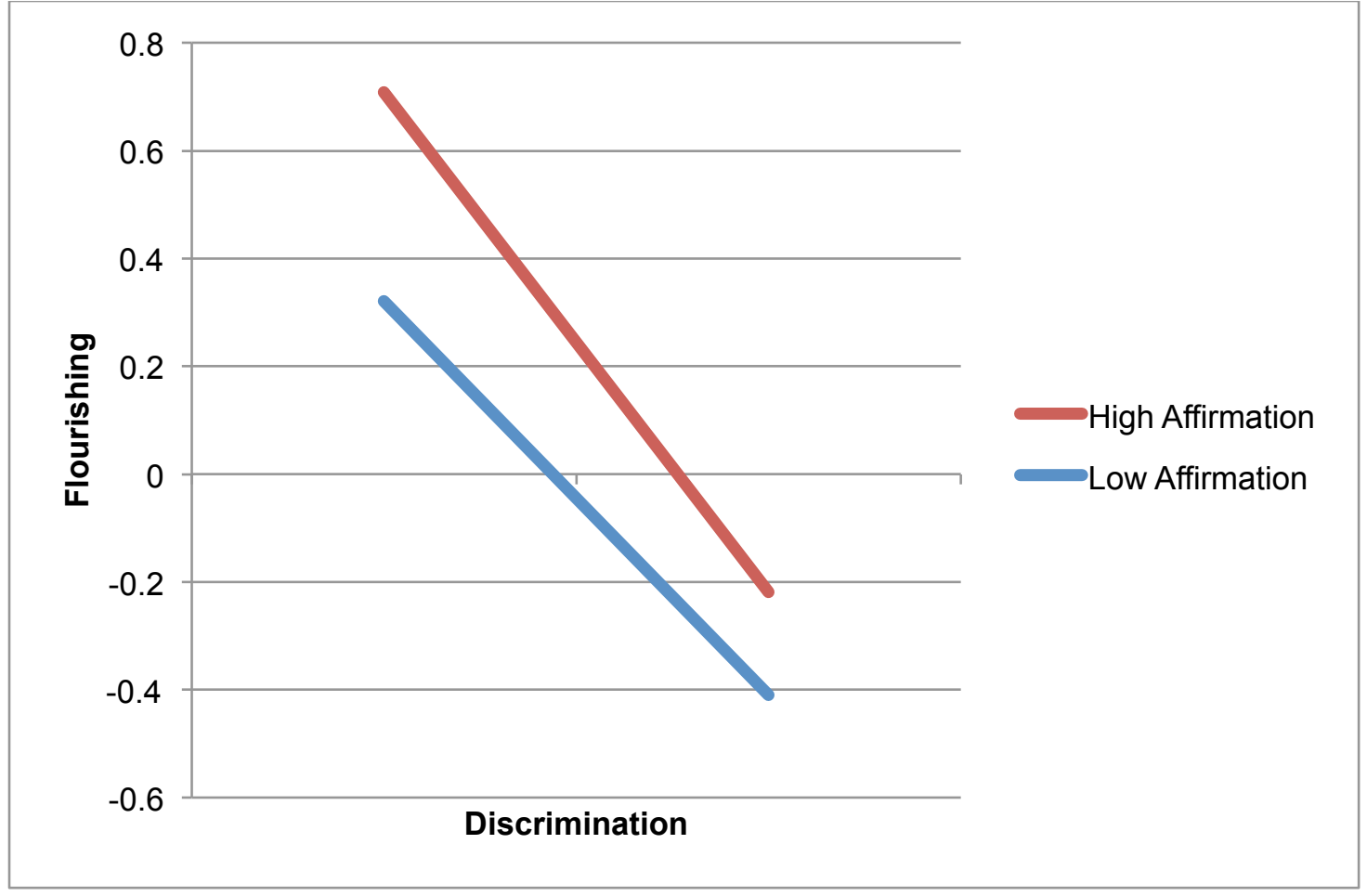


Table 7

Moderated Regression Analysis on Flourishing

\begin{tabular}{|c|c|c|c|c|c|}
\hline Variable & $\mathrm{B}$ & $\mathrm{SE}$ & $\beta$ & $R^{2}$ & $\Delta R^{2}$ \\
\hline Step 1 & & & & .123 & .123 \\
\hline Discrimination & -.322 & .074 & $-.351 * *$ & & \\
\hline Step 2 & & & & .422 & .298 \\
\hline Discrimination & -.182 & .065 & $-.199 *$ & & \\
\hline Exploration & .010 & .077 & .010 & & \\
\hline Resolution & .345 & .080 & $.350 * *$ & & \\
\hline Affirmation & .285 & .080 & $.301 * *$ & & \\
\hline Step 3 & & & & .453 & .031 \\
\hline Discrimination & -.173 & .066 & $-.189 *$ & & \\
\hline Exploration & .019 & .077 & .020 & & \\
\hline Resolution & .344 & .080 & $.349 * *$ & & \\
\hline Affirmation & .197 & .091 & $.208 *$ & & \\
\hline Discrimination $\mathrm{x}$ Exploration & .095 & .094 & .093 & & \\
\hline Discrimination $\mathrm{x}$ Resolution & -.119 & .080 & -.138 & & \\
\hline Discrimination $\mathrm{x}$ Affirmation & .137 & .068 & $.198 *$ & & \\
\hline
\end{tabular}




\section{Satisfaction with life}

In Step 1, results revealed that perceived discrimination did not predict satisfaction with life significantly, $F(1,137)=3.26, p=.07, \Delta R^{2}=.02$ (see Table 8). Ethnic identity dimensions were entered in Step 2, and the equation accounted for $19 \%$ of the variance, $F(3,134)=9.48, p$ $<.001, \Delta R^{2}=.17$. In Step 3, the interaction effects between ethnic identity dimensions and perceived discrimination were not significant, although resolution was still significant and affirmation became significant, $F(3,131)=1.27, p=.29, \Delta R^{2}=.02$.

In summary, Hypothesis 1 that perceived discrimination would predict psychological well-being was partially supported: perceived discrimination predicted self-esteem and flourishing negatively, but it did not predict life satisfaction significantly. Hypothesis 2 , that ethnic identity dimensions would predict psychological well-being, also was partially supported: resolution and affirmation, but not exploration, predicted all the three components of psychological well-being positively. Hypothesis 3 , that ethnic identity dimensions would buffer against perceived discrimination on psychological well-being, was partially supported: affirmation buffered against perceived discrimination only on flourishing. 
Table 8

Moderated Regression Analysis on Satisfaction with Life

\begin{tabular}{|c|c|c|c|c|c|}
\hline Variable & $\mathrm{B}$ & $\mathrm{SE}$ & $\beta$ & $R^{2}$ & $\Delta R^{2}$ \\
\hline Step 1 & & & & .023 & .023 \\
\hline Discrimination & -.152 & .084 & -.152 & & \\
\hline Step 2 & & & & .194 & .171 \\
\hline Discrimination & -.049 & .083 & -.049 & & \\
\hline Exploration & -.083 & .092 & -.084 & & \\
\hline Resolution & .387 & .101 & $.262 * *$ & & \\
\hline Affirmation & .172 & .100 & .168 & & \\
\hline Step 3 & & & & .175 & .023 \\
\hline Discrimination & -.028 & .085 & -.028 & & \\
\hline Exploration & -.109 & .095 & -.111 & & \\
\hline Resolution & .410 & .102 & $.384 * *$ & & \\
\hline Affirmation & .243 & .115 & $.238 *$ & & \\
\hline Discrimination x Exploration & .049 & .117 & .046 & & \\
\hline Discrimination $\mathrm{x}$ Resolution & -.172 & .102 & -.183 & & \\
\hline Discrimination $\mathrm{x}$ Affirmation & -.011 & .086 & -.015 & & \\
\hline
\end{tabular}

$* * p<.001, * p<.05$ 


\section{CHAPTER V: DISCUSSION}

Research on the construct of ethnic identity in Arab Americans has been limited and far behind in comparison to research with other ethnic minority groups (Lee, 2003; Phinney, 2003). With other minority groups, ethnic identity appears to be an important psychological source of resilience (Phinney, 1991). Since Arab Americans are faced with an environment of discrimination and prejudice, it is important to determine whether any factors of resilience are available for this community. Exploring factors of resilience can aid those working in the mental health field by giving clinicians the knowledge and tools to use with Arab American clients struggling with a myriad of issues. Although past literature has scarcely examined ethnic identity in Arab Americans, the goal of the current study was to determine whether ethnic identity could also serve as a protective factor by buffering the impact of discrimination and promoting psychological well-being among this community.

The current study addresses another gap in the available literature on Arab Americans by examining components of psychological well-being rather than psychological distress (e.g., Sirin \& Fine, 2007; Moradi \& Hassan, 2004). In order to gain a better overall picture of mental health, it is necessary to study components of psychological well-being (Winefield, Hill, Taylor, \& Pilkington, 2012). Therefore, the current study examined the negative contribution of discrimination on selfesteem, flourishing, and satisfaction with life.

\section{Description of Study Variables}

I compared the mean scores of the study variables to either norms on the scales when available or mean scores of comparable samples in previous studies to examine whether my sample of Arab Americans differed on them in any meaning way. 
First, the level of perceived discrimination — operationalized as the number of racist events they have encountered within the past year- of this current sample was lower than that of a previous sample of Arab Americans where higher endorsement of racist events reflected greater frequency of discrimination (Willem, 2012). Although there is no norm for the measure used, this result may reflect the current sociopolitical context that is unfavorable to Arab Americans. With the aftermath of the 9/11 attacks and the current attacks carried out by ISIS, Arab Americans continue to experience acts of prejudice, discrimination, hostility, and negativity on a daily basis (Naeem, 2015; Disha, Cavendish, \& King, 2011; Howell \& Shyrock, 2003).

Despite this perceived discrimination, Arab Americans in this sample reported similar levels of flourishing and satisfaction with life to the norms for a diverse sample of Americans at large within the United States (Diener \& Biswas-Diener, 2008; Pavot \& Diener, 1993). Arab-American specific norms or data were not available. Their self-esteem was also comparable to that among another sample of Arab Americans (Moradi \& Hasan, 2004). Arab Americans in this sample, in fact, showed higher levels of Exploration and Resolution of ethnic identity than a sample of ethnic minority university students examined in Umaña-Taylor et al.'s (2004) study, the only study that examined the level of ethnic identity on the three dimensions. The degree of the affirmation was not different between the two samples. It is possible that other demographic factors may influence degree of affirmation, such as geographic location, because areas with a greater population of Arab Americans may be more likely to attribute positive feelings and values towards the Arab culture due to increased exposure to cultural traditions and norms. 


\section{Ethnic Identity Status among Arab Americans}

In examining ethnic identity, this study used the most recent conceptualization that includes the three dimensions of exploration, commitment, and affirmation of ethnic identity (Umaña-Taylor et al., 2004). In the previous literature on ethnic identity (e.g., Phinney, 1996), affirmationpositive regards toward one's ethnic group and identity — has been assumed to be subsumed under resolution - commitment to one's ethnic identity, because one would feel good about one's ethnic identity to be able to commit oneself to it. However, Umaña-Taylor (2004) argued that is not always the case, and suggested that affirmation and resolution need to be differentiated from one another and studied independently. These three ethnic identity dimensions have been examined among Latino/a, Asian, and African Americans, but not among Arab Americans.

Similar to self-identity (Erikson, 1968; Marica, 1996), one's ethnic identity status can be determined depending on one's standing on each dimension (Phinney, 1989; Umaña-Taylor et al., 2004). Then, people with the same status could be grouped into a cluster. Umaña-Taylor and colleagues (2004) were the only ones to my knowledge that tried to identify the eight possible ethnic identity statuses based on the high or low combinations of the three dimensions among diverse racial ethnic minorities in America but not among Arab Americans. They used $k$-mean cluster analysis to force all the eight clusters to the sample and found the eight clusters showed levels of exploration, resolution, and affirmation that were consistent with the expected labels among Asians. For White, Latino, Black, and Multi-ethnic/racial groups, about 6 clusters were identified.

The hierarchal cluster analysis yielded 4 ethnic identity clusters of Achieved Positive, Moratorium Positive, Diffuse Negative, and Diffuse Positive for Arab Americans. A majority of participants have achieved ethnic identity (i.e., making commitment after exploring their ethnicity) 
with an affirming attitude toward their Arab American heritage (i.e., Achieved Positive). Some participants were in the process of exploring their Arab heritage, although they had not made a commitment to their ethnic identity, but still felt positively toward their heritage (i.e., Moratorium Positive). In fact, approximately $90 \%$ of my sample in fact showed a positive attitude toward their ethnicity (i.e., high affirmation), regardless of whether they have explored or committed to their ethnic identity (i.e., all the three clusters except for Diffuse Negative). The remaining 10\%, however, was marginalized from the ethnic identity exploration process and distanced from it with negative attitudes toward their own heritage (i.e., Diffuse Negative). Therefore, it appears that individuals can have high affirmation towards their ethnic group without having explored or resolved their ethnic identity, supporting Umaña-Taylor's (2004) conceptualization.

An important aspect to consider is the level of the ethnic identity dimensions for particular clusters because certain dimensions were relatively close to the mean compared to others that strayed from the mean at considerably higher levels. Affirmation for Diffuse Positive was barely above the mean and considered high. In other words, although participants who fell into this cluster demonstrated high affirmation, they experienced low exploration and resolution at greater degrees. For this reason, the label "Diffuse Neutral" may be a more appropriate name for this particular cluster. This cluster may be representative of marginalized individuals, who as suggested by Berry \& Kim (1988), are individuals that may experience a lack of clarity in terms of who one is as a cultural being and these individuals are more likely to reject cultural practices. This is similar to the dimension of exploration for Moratorium Positive, which barely made it above the mean and was considered high. Participants who fell into the Moratorium Positive cluster demonstrated considerably lower resolution than high exploration because of how close the exploration score was to the mean. The current results may further support the notion that ethnic identity has different 
meanings for individuals in varying minority groups, and certain groups may dominate certain classifications more than other groups (Umaña-Taylor et al., 2004).

This finding may suggest that Arab Americans may have similar experiences with ethnic identity formation as other ethnic and racial minority groups. A majority of the ethnic minority individuals in Umaña-Taylor and colleagues' (2004) sample fell into the Achieved Positive category, similar to that of the current sample, whereas a majority of Whites fell into the Diffuse Positive category. Like for the other racial ethnic minorities, ethnic identity is a more salient cultural dimension for Arab Americans compared to their White counterparts (Phinney, 1989, 1992; Umaña-Taylor et al., 2004).

Possible reasons that these four specific clusters (vs. all eight possible clusters) were identified in this specific sample of Arab Americans may include participants' geographic locations and increased opportunity for exposure to Arab culture. In a study conducted by Amer (2007), cultural identity referred to the degree that an individual was influenced by both the American culture and the Arab culture. Participants with stronger Arab identities were more likely to use Arabic at home and be exposed to Arabic television (Amer, 2007). The current sample reported exposure to both the English and Arabic language at home. An additional dimension reported was the number of visits respondents took to the Arab world, with a mean of 5.94 trips to the Arab world. Three of the four clusters that emerged were characterized by high affirmation, meaning that a majority of participants felt positively towards being Arab. This may be reflective of what scholars suggest, that in order to develop a positive sense of ethnic identity, children need to be influenced by an ethnic community that provides positive exposure (Rosenthal \& Hrynevich, 1985; Liebkind \& Jasinskaja-Lathi, 2000). 


\section{Perceived Discrimination and Psychological Well-Being}

Another main purpose of this study to examine the relationship between perceived discrimination and psychological well-being among Arab Americans. As expected, the results demonstrated that perceived discrimination was significantly negatively related to self-esteem and flourishing, although it was not significantly related to satisfaction with life. This finding is consistent with previous studies that showed that increased perceived discrimination was related to decreased self-esteem and elevated symptoms of depression and anxiety in minority groups including Arab Americans (Amer, 2007), African Americans (Moradi \& Subich, 2003), and Asian Americans (Greene, Way, \& Pahl, 2006). Results are also consistent with previous studies that suggest that experiences with discrimination are detrimental to the mental health of people of color (Garica Coll et al., 1996). However, the link between perceived discrimination and psychological well-being (vs. psychological distress) has been explored only minimally among Arab Americans. The current findings add to the limited body of literature available and provide a better understanding of the impact that perceived discrimination has on the overall mental health on the Arab American population. Results suggest that discrimination may also influence positive components of well-being, such as self-esteem and flourishing.

The measure of satisfaction with life assesses how well an individual thinks they are doing in other aspects of life such as social relationships, physical health, income, spirituality and leisure (Diener et al., 1985). Current results demonstrate that perceived discrimination may not impact other domains of an individual's life such as their social relationships or leisure time. Perhaps religion and community may serve as protective factors against perceived discrimination. People who score high on satisfaction with life typically do not have problems with addictions, such as gambling, drugs, or alcoholism. This may be reflective of the current sample because a majority of 
the participants identified as Muslim, and the Islamic faith does not allow the consumption of alcohol, use of drugs, or gambling (Al-Qaradawi, 1999). Additionally, people who score high on life satisfaction usually have a close and supportive family system. This may reflect the collectivist values of the Arab culture that promote group harmony and interdependence (Sheldon et al., 2015; Walters, 1999). This suggests that future research may look into these speculations further.

\section{Ethnic Identity and Psychological Well-Being}

Ethnic identity is a multidimensional construct and can be understood in terms of the degree to which an individual has explored their ethnicity, the degree to which an individual has resolved what their ethnicity means to mean, and the affect (positive or negative) that an individual associates with their resolution (Umaña-Taylor et al., 2004). Literature has shown that positive and well-established ethnic identity is associated with various positive outcomes such as happiness and positive affect among racial ethnic minorities. In the current sample of Arab Americans, the results showed that, as predicted and consistent with the literature, resolution and affirmation positively predicted all three components of psychological well-being. However, exploration did not predict any of the psychological well-being variables, similar to a previous study conducted with Arab Americans (Sheldon et al., 2015). In other words, participants who were more likely to commit to an identity and feel positively towards being Arab demonstrated higher psychological well-being, although the degree of exploration a participant reported did not have a significant association with well-being.

First, the current findings on resolution positively predicting well-being provide support for existing literature, and additionally, falls in line Tajfel's Social Identity Theory (1981). UmañaTaylor and colleagues (2004) found that resolution was positively related to self-esteem among both ethnic minority and White adolescents. Although research focusing on Arab Americans is 
scarce, one study found that commitment (i.e., resolution) to an Arab identity positively predicted purpose in life among a sample of Arab American college students (Sheldon, Oliver, \& Balaghi, 2015). This may be because an individual's feeling of belongingness to an ethnic group enhances self-esteem, as suggested in the Social Identity Theory (Tajfel, 1981). The theory proposed by White and Burke (1987) may also provide further explanation for the current results. The theorists suggest that when an individual chooses to identify with their ethnicity, they internalize roles and expectations embedded within their ethnic heritage (White \& Burke, 1987). Those roles and expectations give individuals a scope to develop specific goals and outlooks, which leads to purpose in life (Thoits, 1991). Purpose in life is a component of psychological well-being (Sheldon et al., 2015), similar to flourishing and satisfaction with life. It appears that resolution may have a positive relationship with multiple components of psychological well-being including self-esteem, flourishing, life satisfaction, and purpose in life.

Second, similar to resolution, ethnic identity affirmation was significantly and positively related to the well-being components of self-esteem, flourishing, and satisfaction with life. These findings further support previous research conducted by Umaña-Taylor and colleagues (2004) who found that affirmation was positively related to self-esteem for both ethnic minority and White adolescents. In a study by Sheldon and colleagues (2015), which focused specifically on Arab American adolescents, participants who demonstrated higher ethnic identity affirmation and belonging also demonstrated greater self-acceptance. According to Tajfel's Social Identity Theory (1981), when an individual experiences a positive sense of group membership, which, in turn, leads to positive emotional attachment and feelings of belongingness. Therefore, ethnic identity strengthens and leads to increased self-esteem (Tajfel, 1981). 
Third, contrary to hypothesis, exploration was not significantly related to any psychological well-being variables. Erikson (1968) and Phinney's (1990) theories of identity development may explain this finding. The theorists posit that exploration is a time of uncertainty and instability in an individual's identity development that may be met with internal conflict. Consistently, Arab American adolescents who scored lower on the dimension of exploration also scored lower on selfacceptance (Sheldon et al., 2015). However, exploration was significantly associated with selfesteem among ethnic minority adolescents from varying ethnic backgrounds (e.g., Asian, Latino/a, African, Mixed, Umaña-Taylor et al., 2004). It is possible that, contrary to other racial/ethnic minorities, exploration may not be a contributing factor to psychological well-being for Arab Americans. In an attempt to self-identity, Arab Americans may feel the need negotiate to their opposing heritage culture and American culture. This negotiation may be more conflicting for Arab Americans than other ethnic minorities groups because Arabs are categorized as White on the U.S. Census forms, although, in one particular study, Arab adolescents did not self-identify as "white" (Ajrouch, 2004). The contradiction of classification as 'White' while 'Arab' has forced Arab Americans to negotiate their ethnic identity unlike most other ethnic minority groups (Howell \& Shyrock, 2003; Naber, 2000). Exploration may have a different meaning for Arab Americans in particular due to this contradiction, which may lead to an internal conflict during the negotiation process and cause exploration of their heritage culture to be a time met with distress.

Overall, results demonstrate that ethnic identity resolution and affirmation are not only related to self-esteem but have significant relationships with other components of psychological well-being that the existing body of literature has not examined. Ethnic identity exploration and resolution with positive affirmation were associated with life satisfaction, happiness, and positive affect with Latino/as (e.g., Umaña-Taylor \& Updegraff, 2007) and Asian Americans (e.g., Lee \& 
Yoo, 2004). It appears that Arab Americans have similar yet unique experiences with ethnic identity development when compared to other ethnic minority groups. Like other minority groups, having a firm identity as a member of Arab Americans and an affirming attitude toward one's own heritage appear to help Arab Americans feel good about themselves, be happy with their lives, and have a feeling of psychological fulfillment. Unlike other minority groups, however, exploration may cause unique inner conflict for Arab Americans, which warrants further research to better understand the process of ethnic identity development among this population.

\section{Ethnic Identity as Buffer against Perceived Discrimination}

Ethnic identity is considered to be one of the most important psychological resources that contribute to an individual's resilience (Phinney, 1990; Phinney, 2003). Because Arab Americans are at increasing risk for acts of discrimination and prejudicial attitudes, it is important to explore the resources available to this community that may allow them to prosper in times of adversity. Research suggests that ethnic identity may serve as a protective factor for Arab Americans by buffering the detrimental impacts of discrimination (e.g., Willems, 2012) and improving psychological well-being (Sheldon et al., 2015; Ahmed et al., 2011). Results indicated that the dimension of affirmation served as a moderator between perceived discrimination and flourishing. Specifically, the association between perceived discrimination and flourishing was smaller for those who endorsed higher levels of affirmation compared to those who scored lower on affirmation. Although this study was correlational, this result suggests a possibility that ethnic identity affirmation may mitigate the negative impact of perceived discrimination on flourishing. Tajfel's (1981) Social Identity Theory and Crocker and Major's (1989) theory on self-protecting functions of external attributions may explain this finding further. Tajfel's (1981) social identity theory suggests that an individual develops a sense of identity through feelings of belonging to a particular 
group, with the accompanying component of a positive sense of group membership. Therefore, ingroup identification accompanied by affirmation may provide an individual with resources and assets that give them a sense of security, belongingness, social support, and stability (Tajfel \& Turner, 1986). Those resources could contribute to an individual's resilience, and, in turn, protect against the effects of adverse experiences such as discrimination (Sandler, 2001). Crocker and Major (1989) state that the more an individual identifies with a group that is discriminated against or devalued in society, the more likely the individual will be able to use group-level self-protective strategies to combat the negative impacts of discrimination. Another reason that ethnic identity affirmation may contribute as a buffer against perceived discrimination could be its relationship with active coping with discrimination. In previous research, Latino/a Americans, African Americans, Japanese Americans, and Mexican Americans with high ethnic identity (i.e., exploration and resolution with positive affirmation) used active coping strategies to deal with discrimination rather than passive coping styles (Chavira \& Phinney, 1991).

In addition, the unique contribution of this study is that it demonstrated the potential protective component of ethnic identity might be the affirmation dimension, rather than resolution, although previous theories have assumed that ethnic identity resolution is always accompanied by positive affect. Therefore, measuring the dimensions of resolution and affirmation independent of one another may be important for future research to keep in mind.

Then, why does ethnic identity affirmation buffer against perceived discrimination only on flourishing? Scholars suggest that flourishing goes beyond pleasure and emotional feelings of happiness, and, instead, assesses an individual's contributions to society and the happiness of others (Diener et al., 2009). An individual may be flourishing even in times of emotional trouble and other times may be feeling emotionally well but not flourishing. Thus, positive Arab American identity 
may not protect a person from the temporary distress of discrimination, but may allow the individual to flourish in life despite the discrimination and concurrent distress or temporarily undermined self-esteem. Self-esteem and satisfaction with life reflect an individual's sense of selfworth (Diener et al., 1985; Rosenberg, 1965) rather than external aspects of well-being such as strong social relationships, engaging work, and a sense of purpose and value in life. It is important to parse out what components of ethnic identity may serve as a factor for resilience in minority populations who deal with adversity due to the current sociopolitical context. For Arab Americans, it appears that ethnic identity affirmation, or feeling positively toward their ethnic group, serves as a component of resilience by mitigating the negative impact of discrimination on promoting flourishing. Future research should test this speculation on whether external aspects of well-being may be more likely to be influenced by ethnic identity than internal aspects of well-being.

\section{Limitations}

There are several limitations to the current study. Beginning with recruitment, a non-random sample was used to collect and analyze data. The sample was not randomly drawn from the population at large, and, instead, the primary researcher reached out to several Arab and/or Muslim organizations and mosques via email or social media to disperse the online survey. A large majority of the organizations and mosques contacted were located in the Midwest, which may indicate that results are more representative of Arab Americans living in Midwestern cities. A snowball method was also put into place where respondents were asked to pass the survey along to those who fit the eligibility requirements.

Because of the recruitment methods used, individuals who are isolated or not affiliated with an Arab and/or Muslim community may have been underrepresented in the current study. The sample may be more representative of individuals with high ethnic identity because participants 
were recruited from Arab-identified and Muslim-associated groups, and the salience of Arab identity may be stronger in members of these organizations than the population in general. Conversely, individuals who may be more assimilated to American mainstream culture may not seek out these groups and were less likely to be reached to participate in the current research study. Therefore, generalizability of results may be limited to this convenience sample with potentially higher level of ethnic identity.

Relatedly, the English-only measures of the survey were a limitation to the current study. Monolingual Arabic speakers were not present in this study because participants needed to selfidentify as proficient in English to complete the survey. Those who felt that their English was not proficient enough to complete the survey may have opted out of participating, or those who misjudged their level of English fluency may have had a difficult time understanding the English used. Since acquisition of the mainstream culture's primary language is a key component of acculturation, the current sample may be more reflective of the experiences of individuals with a higher level of acculturation. Given that a majority of the participants were born in the United States, identified English as their primary language, and demonstrated high ethnic identity, this sample may be more representative of integrated individuals. Therefore, Arab Americans lacking proficiency in English and with lower levels of acculturation seem to be underrepresented in the current study.

\section{Clinical Implications}

A majority of research studies currently published on Arab Americans focus on measures of psychological distress, such as externalizing behaviors and symptoms of depression or anxiety (Amer, 2007; Siring \& Fine, 2007; Sayed \& Galea, 2009). The current study illustrates the importance of studying components of psychological well-being in order to gain a better overall 
picture of Arab American mental health. Given the current social climate of stigmatization, prejudice, and discrimination (Ibish, 2003), it is vital to understand not only what causes psychological distress but also what could enhance and protect their psychological well-being (Winefield, Hill, Taylor, \& Pilkington, 2012).

The current study not only adds to the existing body of literature by addressing psychological well-being, but it provides further knowledge for mental health practitioners serving Arab Americans. Findings in the current study suggest that ethnic identity resolution and affirmation are indicators of positive psychological well-being among Arab Americans. Also, ethnic identity affirmation proved to be a protective factor against discrimination. As such, these dimensions of ethnic identity should be considered with high regard when providing mental health services for Arab American clients. Perhaps clinicians could address internalized racism to disconfirm the undue prejudice that Arab Americans may hold toward themselves, thereby increasing their sense of affirmation towards their group. Clinicians could also explore what their ethnicity means to them in order to engage in the process of ethnic identity formation. Also, discussing multiple aspects of well-being may allow clinicians to gain a better understanding of an individual's psychological functioning. For example, it would be empowering to Arab American clients if they could become more aware of the fact that, although they may be feeling hurt and distressed due to perceived discrimination, they are and can be still prospering using their own resilience and strength. However, clinicians should be cautious in approaching clients because victim blaming may occur when the client is encouraged to just deal with discrimination as a part of life. Clinicians need to be sensitive in recognizing the influence of systematic discrimination on the lives of racial and ethnic minority individuals living in the United States. 


\section{Future Considerations}

Research on the Arab American population is in its early stages, and further studies need to be conducted in order to better understand the unique characteristics and needs of this population. Because this is the first known use of Umaña-Taylor and colleagues, (2004) ethnic identity typology, further research needs to be conducted in order to determine whether the identity clusters that emerged can be replicated in a more representative sample of Arab Americans.

Since the current study examined ethnic identity as a potential protective factor against discrimination, future studies should take into consideration varying factors that may influence ethnic identity and moderate the relationship between ethnic identity and other outcome variables (e.g., distress, well-being), such as generational status, acculturation, geographic location, and religion. The current study had a sample that appears to be more representative of secondgeneration Arab Americans who predominately speak English at home. It has been argued that as generations move further away from the direct immigration experience, one's ethnic group membership is likely to shift, and belongingness diminishes as acculturation takes place (Cameron \& Lalonde, 1994). For that reason, generational status and acculturation may be predictors that could contribute to the exploration of one's ethnic culture. One manner of targeting generational status may include offering measures in the Arabic language for individuals who feel they can best express themselves in their native language. An additional measure targeting acculturation level may also be added to the battery of surveys participants' complete.

Another important factor to consider is geographic location. The current sample of Arab Americans was recruited from a myriad of states in order to increase the participation rates. However, because some geographic locations have higher concentrations of Arab Americans than others, it is important to consider location as a potential influencer of ethnic identity. For example, 
Dearborn, Michigan is a city with a high concentration of Arab Americans. When walking around the city of Dearborn it is common to see signs in Arabic and Middle Eastern stores scattered around the city. Scholars suggest that ethnic identity salience is a result of interactions with groups that are different than one's own group (Fakih, 2014). For that reason, geographic location may be a predictor that contributes to ethnic identity exploration. It could also contribute to resolution and affirmation because locations with a larger Arab community may provide further validation and value towards the culture. If that were the case, geographic location may play a role in buffering the impact of discrimination because an individual's ethnic identity affirmation may be higher.

Therefore, future studies need to be aware of the geographic location participants are coming from and the degree to which the location may impact ethnic identity.

Religion is a considerably important factor to consider as well, because religious beliefs are a component of diversity among the Arab American population. In the current sample, 78\% of Arab Americans identified as Muslim, and the minority identified as Christian at $12 \%$. This sample is not reflective of the American society because a majority 63\% of Arab Americans in the United States identify as Christian (AAI, 2011). Therefore, the current sample is more representative of Arab American Muslims, whom in reality, make up about $25 \%$ of the Arab American population currently residing in the United States (AAI, 2011). Previous research suggests that Arab American Christians are more likely to report greater life satisfaction and acculturation than those who identify as Muslim (Amer \& Hovery, 2005). More over, Arab American Muslims who affirmed their ethnic identity experienced more discrimination compared to Arab American Christians (Awad, 2010). It appears that Arab American Christians and Muslims have different experiences in the United States and religiosity may play an important role in the process of ethnic identity formation and influence experiences with discrimination. Future empirical research should take the 
notion of religion into serious consideration within this population in order to examine differences among the religious groups. These speculations about potential predictors and moderating factors should be researched further.

The current study was one of few available studies that explored the potential power of ethnic identity as a protective factor for Arab Americans. Results generate further question for empirical study on this construct and provide a stepping-stone to discovering factors that contribute to the resilience of this ethnic group. The current study can be used as a tool for mental health clinicians working with clients from the Arab American community and aid clinicians in becoming more knowledgeable about the experiences and needs of this often misrepresented group. Exploring and clarifying potential protective factors for this ethnic group is necessary because Arab Americans face discrimination and prejudicial attitudes often and are likely to underutilize mental health services (Aloud, 2004). By delving more into this topic, researchers can help bridge the barriers to mental health services and increase understanding on an ethnic group that is often marginalized and isolated in society. 


\section{REFERENCES}

Abu-Ras, W., \& Abu-Bader, S. H. (2008). The impact of the September 11, 2001, attacks on the well-being of Arab Americans in New York City. Journal of Muslim Mental Health, 3, $217-$ 239. doi: $10.1080 / 15564900802487634$

Adding a MENA Category to the U.S. Census - Arab American Institute. (2015, May 16). Retrieved September 24, 2016, from http://www.aaiusa.org/2020census

Ahmed, S. R., Kia-Keating, M., \& Tsai, K.H. (2011). A structural model of racial discrimination, acculturative stress, and cultural resources among Arab American Adolescents. American Journal of Community Psychology, 48, 181-192. doi: 10.1007/s10464-011-9424-3

Ajrouch, K. J. (2005). Arab American elders: Network structure, perceptions of relationship quality, and discrimination research. Human Development, 2, 213-228.

Al-Qaradawi, Y. (1999). The lawful and the prohibited in Islam (Al-Halal wal Haram fil Islam). Planfield, IN: American Trust Publications.

Aloud, N. (2004). Factors affecting attitudes toward seeking and using formal mental health and psychological services among Arab-Muslims population. ProQuest Information and Learning. Dissertation-Abstracts-International-Section-A:-Humanities-and-SocialSciences, $65(3-\mathrm{A}), 1113$.

Amer M. M., \& Hovey J. D. (2007). Socio-demographic differences in acculturation and mental health for a sample of 2nd generation/early immigrant Arab Americans. Journal of Immigrant and Minority Health, 9, 335-47. doi:10.1007/s10903-007-9045-y.

American-Arab Anti-Discrimination Committee. (2002). Fact sheet: The condition of Arab Americans post-September 11. Retrieved July 10, 2003, from http://www.adc.org/index Arab 
Arab American Institute. (2007). Arab Americans socio-demographics. Retrieved from http://www.aaiusa.org/foundation/34/censusinformation-center

Arab American Institute. (2011). Quick Facts about Arab Americans. Retrieved from https://d3n8a8pro7vhmx.cloudfront.net/aai/pages/9843/attachments/original/1432919063/qui ckfacts.pdf?1432919063

Arab American Institute. (2012). Arab American demographics. Washington, DC: Zogby International.

Arab American National Museum \& Institute of Museum and Library Services. (2000). Arab Americans: An integral part of American society. Dearborn, MI.

Beitin, B., \& Allen, K. R. (2005). Resilience in Arab American couples after September 11, 2001: A systems perspective. Journal of Marital and Family Therapy, 31, 251-267.

Berry, J. W., \& Kim, U. (1988). Acculturation and mental heath. In P. Dasen, J. W. Berry, \& N. Sartorius (Eds.), Health and cross-cultural psychology (pp. 207-236). London: Sage.

Bouffard, K. (2004). Arab American teens struggle with rising stress. The Detroit News.

Brittingham, A., \& G. P. de la Cruz. (2005). We the people of Arab ancestry in the United States. U.S. Census Bureau Special Reports. Washington, D.C.: Government Printing Office. Retrieved from https://www.census.gov/prod/2005pubs/censr-21.pdf

Britto, P. R. (2008). Who am I? Ethnic identity formation of Arab Muslim children in contemporary U.S. society. Journal of American Academy of Child and Adolescent Psychiatry, 47, 853-857. doi: 10.1097/CHI.0b013e3181799fa6

Bushman, B. J., \& Bonacci, A. M. (2004). You've got mail: Using e-mail to examine the effect of prejudiced attitudes on discrimination against Arabs. Journal of Experimental Social Psychology, 40, 753-759. doi:10.1016/j.jesp.2004.02.00 
Cameron, J. E., \& Lalonde, R. N. (1994). Self, ethnicity, and social group memberships in two generations of Italian Canadians. Personality and Social Psychology Bulletin, 20, 514-520. doi: $10.1177 / 0146167294205008$

Chavira, V., \& Phinney, J. S. (1991). Adolescents' ethnic identity, self-esteem, and strategies for dealing with ethnicity and minority status. Hispanic Journal of Behavioral Sciences, 13, $226-227$.

CNN.com. (2002, November 25). FBI: Hate crimes targeting Muslims, Middle Easterners surged in 2001. Retrieved November 25, 2002, from http://www.cnn.com/2002/LAW/11/25/hate.crimes.ap/indez.html.

Corning, A. F. (2002). Self-esteem as a moderator between perceived discrimination and psychological distress among women. Journal of Counseling Psychology, 49, 117-126.

Crocker, J., \& Major, B. (1989). Social stigma and self-esteem: The self-protective properties of stigma. Psychological Review, 96, 608-630. doi: 10.1037/0033- 295X.96.4.608.

Diener, E., Emmons, R. A., Larsen, R. J., \& Griffin, S. (1985). The Satisfaction with Life Scale. Journal of Personality Assessment, 49, 71-75.

Diener, E., Wirtz, D., Tov, W., Kim-Prieto, C., Choi, D., Oishi, S., \& Biswas-Diener, R. (2009). New measures of well-being: Flourishing and positive and negative feelings. Social Indicators Research, 39, 247-266.

Disha, I., Cavendish, J. C., \& King, R. D. (2011). Historical events and spaces of hate: Hate crimes against Arabs and Muslims in post-9/11 America. Social Problems, 58, 21-46. doi:10.1525/sp. 2011.58.1.21 
El-Sayed, A., \& Galea, S. (2009). The health of Arab-Americans living in the United States: A systematic review of the literature. BMC Public Health, 9, 1-9. doi: 10.1186/1471-2458-9272

Erikson, E. H. (1968). Identity: Youth and crisis. New York: Norton.

Fakih, R. R. (2013). Ethnic identity among Arab Americans: An examination of contextual influences and psychological wellbeing. Wayne State University Dissertations. Paper 881.

Finch, B. K., Kolody, B., \& Vega, W. A. (2000). Perceived discrimination and depression among Mexican-origin adults in California. Journal of Health and Social Behavior, 41, 295-313. doi: $10.2307 / 2676322$.

Fordyce, M. W. (1988). A review of research on happiness measures: A sixty-second index of happiness and mental health. Social Indicators Research, 20, 355-381. doi:10.1007/BF00302333.

García Coll C., Lamberty G., Jenkins R., McAdoo H. P., Crnic K., Wasik B. H., Vázquez García H. (1996). An integrative model for the study of developmental competencies in minority children. Child Development, 67, 1891-1914.

Garica Coll, C., \& Magnuson, K. (1997). The psychological experience of immigration: A developmental perspective. In A. Booth, A. C. Crouter, \& N. Landale (Eds.), Immigration and the family: Research and policy on U.S. immigrants (pp. 91-132). Mahwah, NJ: Lawrence Erlbaum.

Ghanem-Ybarra, G. J. (2003). The acculturation process and ethnic self-identification of secondgeneration Christian Palestinian American women. Unpublished doctoral dissertation, California Professional School of Psychology at Alliant International University, San Diego. 
Greene M. L., Way N., Pahl K. (2006). Trajectories of perceived adult and peer discrimination among black, Latino, and Asian American adolescents: Patterns and psychological correlates. Developmental Psychology, 42, 218-236.

Hayes, A. F. (2012). PROCESS: A versatile computational tool for observed variable mediation, moderation, and conditional process modeling [White paper].

Howell, S., \& Shyrock, A. (2003). Cracking down on diaspora: Arab Detroit and America's “war on terror." Anthropological Quarterly, 76, 443-462. doi:10.1353/anq.2003.004

Ibish, I. (2001). 1998-2000 report on hate crimes and discrimination against Arab Americans. Washington, DC: American-Arab AntiDiscrimination Committee.

Ibish, I. (2003). Report on hate crimes and discrimination against Arab Americans: The postSeptember 11 backlash, September 11, 2001-October 11, 2002. Washington, DC: AmericanArab Anti-Discrimination Committee.

Ibish, I. (2008). Report on hate crimes and discrimination against Arab Americans: 2003-2007. Retrieved from http://www.ibishblog.com/ book/ 2008 /04/28 /report_hate_crimes_and_discrimination_against_arab_americans_2003_2007 immigrants

Jamal, A. (2008). Mainstream America's silence: The racialization of Arab Americans. In A. Jamal \& N. Naber (Eds.), From invisible citizens to visible subjects (pp. 318-326). Syracuse, NY: Syracuse University Press.

Josselson, R. (1994). The theory of identity development and the question of intervention: An introduction. In S. L. Archer (Ed.), Interventions for adolescent identity development (pp. 12-25). Thousand Oaks, CA: Sage. 
Karlamangla A., Zhou K., Reuben D., Greendale G., \& Moore A. (2006). Longitudinal trajectories of heavy drinking in adults in the United States of America. Addiction, 101, 9199.

Laffrey, S. C., Meleis, A. I., Lipson, J. G., Solomom, M., \& Omidan, P. A. (1989). Assessing Arab-American health care needs. Social Science Medicine, 29, 877-833.

Landrine, H., \& Klonoff, E. A. (1996). The Schedule of Racist Events: A measure of racial discrimination and a study of its negative physical and mental health consequences. Journal of Black Psychology, 22, 144-168. doi: 10.1177/ 00957984960222002

Lee, R. (2003). Ethnic identity and other-group orientation protect against discrimination for Asian Americans? Journal of Counseling Psychology, 50, 133-141. doi: 10.1037/00220167.50 .2 .133

Lee, R. M., \& Yoo, H. C. (2004). Structure and measurement of ethnic identity for Asian American college students. Journal of Counseling Psychology, 51, 263-269. doi:10.1037/0022-0167.51.2.263

Liebkind, K., \& Jasinskaja-Lahti, I. (2000). Acculturation and psychological well-being of immigrant adolescents in Finland: A comparative study of adolescent from different cultural backgrounds. Journal of Adolescent Research, 15, 446-469.

Marcia, J. E. (1980). Identity in adolescence. In J. Adelson (Ed.), Handbook of adolescent psychology (pp. 159-187). New York: Wiley.

McAuliffe, G. (2008). Culturally Alert Counseling: A comprehensive introduction. Thousand Oaks, CA: Sage. 310-314

Middle East. (n.d.) Retrieved September 08, 2016, from https://www.britannica.com/place/Middle-East 
Moradi, B., \& Hasan, N. T. (2004). Arab American Persons' Reported Experiences of Discrimination and Mental Health: The Mediating Role of Personal Control. Journal of Counseling Psychology, 51, 418-428. doi: 10.1037/0022- 0167.51.4.418

Moradi, B., \& Subich, L. M. (2003). A concomitant examination of the relations of perceived racist and sexist events to psychological distress for African American women. The Counseling Psychologist, 31, 451- 469.

Naber, N. (2000). Ambiguous insiders: An investigation of Arab American invisibility. Ethnic and Racial Studies, 23, 37-61.

Naeem, N. (2015, November 24). CAIR Reports Unprecedented Backlash Against American Muslims After Paris Attacks. Retrieved September 29, 2016, from https://www.cair.com/press-center/press-releases/13277-cair-reports-unprecedentedbacklash-against-american-muslims-after-paris-attacks.html

Ogden, J. (2012). Health psychology: A textbook. New York: McGraw-Hill International.

Phinney, J. (1989). Stages of ethnic identity development in minority group adolescents. Journal of Early Adolescence, 9, 34-39.

Phinney, J. (1996). Understanding ethnic diversity. The American Behavioral Scientist, 40, 143152. doi: $10.1177 / 0002764296040002005$

Phinney, J. S. (1992). The multigroup ethnic identity measure: A new scale for use with diverse groups. Journal of Adolescent Research, 7, 156-176.

Phinney, J. S. (2003). Ethic identity and acculturation. In K. M. Chun, P. Balls Organista \& G. Marín (Eds.), Acculturation: Advances in theory, measurement, and applied research. (pp. 63-81). Washington, DC US: American Psychological Association. 
Phinney, J. S., \& Chavira, V. (1995). Parental ethnic socialization and adolescent coping with problems related to ethnicity. Journal of Research on Adolescence, 5, 31-53.

Phinney, J. S., Cantu, C. L., \& Kurtz, D. A. (1997). Ethnic and American identity as predictors of self-esteem among African American, Latino, and White adolescents. Journal of Youth and Adolescence, 26, 165-185.

Phinney, J. S., \& Chavira, V. (1992). Ethnic identity and self-esteem: an exploratory longitudinal study. Journal of Adolescence, 15, 271-281.

Phinney, J. S., Horenczyk, G., Liebkind, K., \& Vedder, P. (2001). Ethnic identity, immigration, and well-being: An interactional perspective. Journal of Social Issues, 57, 493-510.

Read, J. G. (2003). The sources of gender role attitudes among Christian and Muslim ArabAmerican women. Sociology of Religion, 64, 207-222.

Read, J. G. (2008). Discrimination and identity formation in a post-9/ 11 era: A comparison of Muslim and Christian Arab Americans. In A. Jamal \& N. Naber (Eds.), Arab Americans before and after 9/ 11: From invisible Citizens to visible subjects (pp. 305-317). New York, NY: Syracuse University Press

Robins, R. W., Hendin, H. M., \& Trzesniewski, K. H. (2001). Measuring global self-esteem: Construct validation of a single-item measure and the Rosenberg Self-Esteem Scale. Personality and Social Psychology Bulletin, 27, 151-161. doi: 10.1177/0146167201272002

Rosenberg, M. (1965). Society and the adolescent self-image. Princeton, NJ: Princeton University Press.

Rosenberg, M. (1979). Conceiving the self. New York: Basic Books. 
Rosenthal, D., \& Hrynevich, C. (1985). Ethnicity and ethnic identity: A comparative study of Greek-, Italian-, and Anglo-Australian adolescents. International Journal of Psychology, 20, 723-742.

Rotherham-Borus, M. J. (1993). Biculturalism among adolescents. In M. E. Bernal, \& G. P. Knight (Eds.), Ethnic identity: Formation and transmission among Hispanic and other minorities (pp. 81-102). Albany, NY: State University of New York Press.

Said, E. W. (1978). Orientalism. London: Penguin Books

Samhan, H. (2000). By The Numbers: Arab American Demographics. Retrieved September 30, 2016, from http://www.allied-media.com/Arab-American/Arab_demographics.htm

Sandler, I. (2001). Quality and ecology of adversity as common mechanisms or risk and resilience. American Journal of Community Psychology, 29, 19-61.

Sellers, R. (2013). The multidimensional mode of black identity. Measurement instrument database for the social science. Retrieved from www.midss.ie

Sellers, R. M., Caldwell, C. H., Schmeelk-Cone, K. H., \& Zimmerman, M. A. (2003). Racial identity, racial discrimination, perceived stress, and psychological distress among African American young adults. Journal of Health and Social Behavior, 44, 302-317. doi:10.1177/0095798410390689

Sellers, R. M., Rowley, S., T. M, Chavous, J. N., \& Mia A. S. (1997). Multidimensional inventory of black identity: Preliminary investigation of reliability and construct validity. Journal of Personality and Social Psychology, 73, 805-815.

Sellers, R. M., Smith, M. A., Shelton, J. N., Rowley, S., \& Chavous, T. M. (1998). Multidimensional model of racial identity: A reconceptualization of African American racial identity. Journal of Personality and Social Psychology Review, 2, 18-39. 
Shaheen, J. (2009). Culture Interview with Jack Shaheen/ Interviewer: P. Harrington [transcript]. Counter Culture. Retrieved from: https://countercultureuk.com/2009/11/25/cultureinterview-with-jack-shaheen/

Shaheen, J. G. (1984). The TV Arab. Bowling Green, OH: Bowling Green State

Sheldon, J. P., Oliver, D. G., \& Balaghi, D. (2015). Arab American emerging adults' ethnic identity and its relation to psychological well-being. Emerging Adulthood, 5, 340-352. doi: $10.1177 / 2167696815597601$

Sirin, S. R., \& Fine, M. (2007). Hyphenated selves: Muslim American youth negotiating identities on the fault lines of global conflict. Journal of Applied Development Science, 11, $151-163$.

Smith, T. B., \& Silva, L. (2011). Ethnic identity and personal well-being of people of color: A meta-analysis. Journal of Counseling Psychology, 58, 42-60. doi. 10.1037/a0021528

Spencer, M. B., Swanson, D. P., \& Cunningham, M. (1991). Ethnicity, ethnic identity, and competence formation: Adolescent transition and cultural transformation. Journal of Negro Education, 60, 366-387.

Suleiman, M., \& Abu Laban, B. (1989). Arab Americans: Continuity and Change, Arab American University Graduates: Washington DC, 1-16.

Swanson, D. P., Spencer, M. B., \& Petersen, A. (1997). Identity formation in adolescence. In K. Borman \& B. Schneiderl (Eds.), The adolescent years: Social influences and educational challenges (97th yearbook of the national society for the study of education, pp. 18-41). Chicago: The National Society for the Study of Education. 
Tajfel, H. (1981). Human groups and social categories. Cambridge, England: Cambridge University Press.

Tajfel, H., \& Turner, J. C. (1986). The social identity theory of inter-group behavior. In S. Worchel and L. W. Austin (eds.), Psychology of Intergroup Relations. Chicago: Nelson-Hal Thoits, P. A. (1991). On merging identity theory and stress research. Social Psychology Quarterly, 54, 101-112.

Griffith, R. A., Beumont, P. J., Giannakopolous, E., Russell, J., Schotte, D., Thornton, C., . . . Varano, P. (1999). Measuring self-esteem in dieting disordered patients: The validity of the Rosenberg and Coopersmith contrasted. International Journal of Eating Disorders, 25, 227231. doi: $10.1002 / 1098-108$

U.S. Census Bureau. (2010). Overview of race and Hispanic origin: 2010. Washington, D.C.: Government Printing Office. Retrieved from http://www.census.gov/prod/cen2010/briefs/c2010br-02.pdf

Umaña-Taylor, A. J., Yazedjian, A., Bámaca-Gómez, M. (2004). Developing the ethnic identity scale using Eriksonian and social identity perspectives. Identity: An international journal of theory and research, 4, 9-38.

Umaña-Taylor, A. J., \& Updegraff, K. A. (2007). Latino adolescents' mental health: Exploring the interrelations among discrimination, ethnic identity, cultural orientation, self-esteem, and depressive symptoms. Journal of Adolescence, 30, 549-567.

doi:10.1016/j.adolescence.2006.08.002

Wagner J. A., Osborn C. Y., Mendenhall E. A., Budris L. M., Belay S., Tennen H. A. (2011). Beliefs about racism and health among African American women with diabetes: A qualitative study. Journal of the National Medical Association, 103, 224. 
Waldo, C. R. (1999). Working in a majority context: A structural model of heterosexism as minority stress in the workplace. Journal of Counseling Psychology, 46, 218-232.

White, C. L., \& Burke, P. J. (1987). Ethnic role identity among Black and White college students: An interactionist approach. Sociological Perspectives, 30, 310-331.

Willems, E. A. (2012). Discrimination and acculturation among Arab Muslim immigrants in the U.S. Received from ProQuest LLC.

Winefield, H. R., Gill, T. K., Taylor, A. W., \& Pilkington, R. M. (2012). Psychological wellbeing and psychological distress: Is it necessary to measure both? Psychology of Well-Being, 2,3. doi: $10.1186 / 2211-1522-2-3$

Wylie, R. (1979). The self-concept (Vol. 2). Lincoln: University of Nebraska Press.

Zogby, J. J. (2002, July). Profiling and prejudice: Arab American attitudes and behavior since September 11. Retrieved January 21, 2008, from http://aai.3cdn.net/d7083bd00cf4ce3240_wfm6ii8b7.pdf 


\section{APPENDIX A: MEASURES}

\section{Socio-demographic Questionnaire}

Please select or fill-in the answer that best describes you. You will not be asked your name or any other identifying information.

1. Location/residence

i. State (drop-down list of 50 states)

2. City/town where you currently live

i. Write in

3. Gender
i. Female
ii. Male
iii. Other (write in)

4. Current Age

i. Drop-down list of ages from 18 to 100

5. Marital Status
i. Single
ii. Engaged
iii. Married
iv. Separated
v. Divorced
vi. Widowed
vii. Domestic partnership
viii. Other (write in)

6. Employment Status (drop-down)

i. Employed for wages

ii. Self-employed

iii. Out of work and looking for work

iv. Out of work but not currently looking for work

v. A homemaker

vi. A student

vii. Military

viii. Retired

ix. Unable to work

7. Highest level of education completed (drop-down)

i. Elementary/grade school

ii. Junior high or middle school

iii. High school degree (e.g., diploma, vocational school, GED)

iv. College/university classes, but no degree yet

v. Associates degree (or 2 years post high school)

vi. Bachelors degree (or 4 years post high school)

vii. Masters degree (or equivalent)

viii. Doctoral degree (or equivalent)

ix. Other (write in) 
8. Father's highest level of education completed

i. Elementary/grade school

ii. Junior high or middle school

iii. High school degree (e.g., diploma, vocational school, GED)

iv. College/university classes, but no degree yet

v. Associates degree (or 2 years post high school)

vi. Bachelors degree (or 4 years post high school)

vii. Masters degree (or equivalent)

viii. Doctoral degree (or equivalent)

ix. Other (write in)

9. Mother's highest level of education completed

i. Elementary/grade school

ii. Junior high or middle school

iii. High school degree (e.g., diploma, vocational school, GED)

iv. College/university classes, but no degree yet

v. Associates degree (or 2 years post high school)

vi. Bachelors degree (or 4 years post high school)

vii. Masters degree (or equivalent)

viii. Doctoral degree (or equivalent)

ix. Other (write in)

10. If you feel comfortable, please list your estimate annual family income before taxes:
i. Less than $\$ 20,000$
ii. $\$ 20,000$ to $\$ 34,999$
iii. $\$ 35,000$ to $\$ 49,999$
iv. $\$ 50,000$ to $\$ 74,999$
v. $\$ 75,000$ to $\$ 99,999$
vi. $\$ 100,000$ or more

11. Religious affiliation
a. Muslim
b. Christian
c. Buddhist
d. Sikh
e. Jewish
f. Hindu
g. None
h. Other (write in)
i. Prefer not to answer

12. In what country were you born? (write in)

13. Were your parent born in the same country? (yes or no)

a. If no, what country was your mother born in? (write in)

b. If no, what country was your father born in? (write in)

14. What is your family's country of origin? (drop-down of 22 Arab countries and prefer not to answer)

15. How many years did you live in the Arab world before immigrating to the U.S.? (drop down from 1-100)

16. How old were you when you immigrated to the U.S.? (drop down from 1-100) 
17. How many years have you lived in the U.S.? (scroll 1-100)

18. How many times have you visited the Arab world? (scroll 1-100)

a. What countries did you visit? (write in)

19. What language do you primarily speak at home?

a. Write in

20. If you feel comfortable doing so, please choose your current legal status to live in the U.S.:

i. U.S. Citizenship/passport

ii. Green Card

iii. Temporary visa - primarily student

iv. Temporary visa - primarily work

v. Temporary visa - primarily vacation

vi. Refugee

vii. Asylum seeker

viii. Decline to answer

ix. Other (write in) 


\section{Ethnic Identity Scale (EIS)}

Using the scale below, indicate your agreement with each item by placing the appropriate number on the line preceding that item.

$1=$ Does not describe me at all

$2=$ Describes me a little

$3=$ Describes me well

$4=$ Describes me very well

1. My feelings about my ethnicity are mostly negative.

2. I have not participated in any activities that would teach me about my ethnicity.

3. I am clear about what my ethnicity means to me.

4. I have experienced things that reflect my ethnicity, such as eating food, listening to music, and watching movies.

5. I have attended events that have helped me learn more about my ethnicity.

6. I have read books/magazines/newspapers or other materials that have taught me about my ethnicity.

7. I feel negatively about my ethnicity.

8. I have participated in activities that have exposed me to my ethnicity.

9. I wish I were of a different ethnicity.

10. I am not happy with my ethnicity.

11. I have learned about my ethnicity by doing things such as reading (books, magazines, newspapers), searching the internet, or keeping up with current events.

12. I understand how I feel about my ethnicity.

13. If I could choose, I would prefer to be of a different ethnicity.

14. I know what my ethnicity means to me.

15. I have participated in activities that have taught me about my ethnicity.

16. I dislike my ethnicity.

17. I have a clear sense of what my ethnicity means to me. 


\section{Flourishing Scale (FS)}

Below are twelve statements with which you may agree or disagree. Using the scale below, indicate your agreement with each item by placing the appropriate number on the line preceding that item.

7 Strongly agree

6 Agree

5 Slightly agree

4 Mixed, or neither agree nor disagree

3 Slightly disagree

2 Disagree

1 Strongly disagree

I lead a purposeful and meaningful life.

My social relationships are supportive and rewarding.

I am engaged and interested in my daily activities.

I actively contribute to the happiness and well-being of others.

I am competent and capable in the activities that are important to me.

I am a good person and live a good life.

I am optimistic about my future

People respect me 


\section{Satisfaction With Life Scale (SWLS)}

Below are five statements with which you may agree or disagree. Using the scale below, indicate your agreement with each item by placing the appropriate number on the line preceding that item. Please be open and honest in your response.

7 Strongly agree

6 Agree

5 Slightly agree

4 Neither agree nor disagree

3 Slightly disagree

2 Disagree

1 Strongly disagree

In most ways, my life is close to my ideal.

The conditions of my life are excellent.

I am satisfied with my life.

So far, I have gotten the important things I want in life.

If I could live my life over, I would change almost nothing. 


\section{Rosenberg Self-Esteem Scale (RSES)}

Choose one for each question:

$4=$ Strongly agree

$3=$ Agree

$2=$ Disagree

$1=$ Strongly Disagree

1. On the whole, I am satisfied with myself.

2. At times I think I am no good at all.

3. I feel that I have a number of good qualities.

4. I am able to do things as well as most other people.

5. I feel I do not have much to be proud of.

6. I certainly feel useless at times.

7. I feel that I'm a person of worth, at least on an equal plane with others.

8. I wish I could have more respect for myself.

9. All in all, I am inclined to feel that I am a failure.

10. I take a positive attitude toward my self. 


\section{Schedule of Racist Events: Arab American version (SRE-AA)}

We are interested in your experiences with racism. As you answer the questions below, please think about your experiences from the past year. For each question, please circle the number that best captures the things that have happened to you. Use these numbers:

Circle $1=$ If this has NEVER happened to you

Circle $2=$ If this has happened ONCE IN A WHILE (less than 10\% of the time)

Circle $3=$ If this has happened SOMETIMES (10\%-25\% of the time)

Circle $4=$ If this has happened A LOT $(26 \%-49 \%$ of the time)

Circle $5=$ If this has happened MOST OF THE TIME (50\%-70\% of the time)

Circle 6 - If this has happened ALMOST ALL OF THE TIME (more than $70 \%$ of the time)

1. How many times have you been treated unfairly by teachers and professors because of your Arab background?

2. How many times have you been treated unfairly by your employers, bosses and supervisors because of your Arab background?

3. How many times have you been treated unfairly by your coworkers, fellow students and colleagues because of your Arab background?

4. How many times have you been treated unfairly by people in service jobs (store clerks, waiters, bartenders, bank tellers and others) because of your Arab background?

5. How many times have you been treated unfairly by strangers because of your Arab background?

6. How many times have you been treated unfairly by people in helping jobs (doctors, nurses, psychiatrists, case workers, dentists, school counselors, therapists, social workers and others) because of your Arab background?

7. How many times have you been treated unfairly by neighbors because of your Arab background?

8. How many times have you been treated unfairly by institutions (schools, universities, law firms, the police, the courts, the Department of Social Services, the Unemployment Office and others) because of your Arab background?

9. How many times have you been treated unfairly by people that you thought were your friends because of your Arab background?

10. How many times have you been accused or suspected of doing something wrong (such as stealing, cheating, not doing your share of the work, or breaking the law) because of your Arab background? 
11. How many times have people misunderstood your intentions and motives because of your Arab background?

12. How many times did you want to tell someone off for being racist but didn't say anything?

13. How many times have you been really angry about something racist that was done to you?

14. How many times were you forced to take drastic steps (such as filing a grievance, filing a lawsuit, quitting your job, moving away, and other actions) to deal with some racist thing that was done to you?

15. How many times have you been called a racist name like terrorist, towel head, or others names?

16. How many times have you gotten into an argument or a fight about something racist that was

done to you or done to somebody else?

17. How many times have you been made fun of, picked on, pushed, shoved, hit or threatened with harm because you are Arab background?

18. Optional: Please describe any other experiences with discrimination you may have experienced and feel are important to share below. [Write in] 